\title{
Why are target interest rate changes so persistent?*
}

\author{
Olivier Coibion \\ College of William and Mary \\ Yuriy Gorodnichenko \\ University of California, Berkeley and NBER
}

College of William and Mary

Department of Economics

Working Paper Number 106

January 2011

\footnotetext{
*We are grateful to Frederic Mishkin and Glenn Rudebusch for helpful comments and Peter Ireland, Giorgio Primiceri, and Glenn Rudebusch for sharing their data with us.
} 
COLLEGE OF WILLIAM AND MARY

DEPARTMENT OF ECONOMICS

WORKING PAPER \# 106

JANUARY 2011

\title{
Why are target interest rate changes so persistent?
}

\begin{abstract}
We investigate the source of the high persistence in the Federal Funds Rate relative to the predictions of simple Taylor rules. While much of the literature assumes that this reflects interest-smoothing on the part of monetary policy-makers, an alternative explanation is that it represents persistent monetary policy shocks. Applying real-time data of the Federal Reserve's macroeconomic forecasts, we document that the empirical evidence strongly favors the interestsmoothing explanation. This result obtains in nested specifications with higher order interest smoothing and persistent shocks, a feature missing in previous work. We also show that policy inertia is present in response to economic fluctuations not driven by exogenous monetary policy shocks. Finally, we argue that the predictability of future interest rates by Greenbook forecasts supports the policy inertia interpretation of historical monetary policy actions.
\end{abstract}

JEL Codes: Taylor rules, interest rate smoothing, monetary policy shocks.

Keywords: E3, E4, E5.

Olivier Coibion

Department of Economics

College of William and Mary

Williamsburg, VA 23187-8795

ocoibion@wm.edu
Yuriy Gorodnichenko

Department of Economics

University of California, Berkeley

Berkeley, CA 94720-3880

ygorodni@econ.berkeley.edu 
"In their discussion of the relative merits of smaller and more frequent adjustments versus larger and less frequent adjustments .... [FOMC] participants generally agreed that large adjustments had been appropriate when economic activity was declining sharply in response to the financial crisis. In current circumstances, however, most saw advantages to a more incremental approach that would involve smaller changes ... calibrated to incoming data."

Minutes of the FOMC videoconference meeting, October $15^{\text {th }}, 2010$.

\section{Introduction}

Why do central banks adjust interest rates only gradually over time? Monetary economists have long recognized that central bankers change the stance of policy in a more gradual manner than would be expected given the short-run volatility in macroeconomic conditions but have not adequately addressed the source of this inertia. The most common interpretation is that it reflects interest rate smoothing. This view suggests that the central bank has a desired interest rate, as in Taylor (1993), which responds to current and expected macroeconomic conditions, but that policy makers move interest rates only gradually toward the desired rate. This inertial policy can anchor the expectations of economic agents and thereby achieve more stable economic outcomes than in the absence of policy inertia (Levin et al. 1999, Woodford 1999). Policy inertia can also be desirable if interest rate volatility enters the loss function of policymakers, as suggested in Woodford (2003). Clarida et al. (2000) document a significant amount of interest rate smoothing in historical U.S. monetary policy decisions. The description of monetary policy in both theoretical and applied work has since then commonly included an interest smoothing motive on the part of monetary policy makers. However, Rudebusch $(2002,2006)$ has suggested an alternative interpretation, namely that the observed inertia in interest rates reflects persistent deviations from the Taylor rule rather than interest rate smoothing. This can be modeled as persistent policy shocks in the Taylor rule, although the broader interpretation of these shocks is that they represent the response of monetary policymakers to factors other than those included in the basic Taylor rule, such as credit market conditions.

Understanding the source of this interest rate persistence is important for several reasons. First, forecasts of the future path of monetary policy will be sensitive to the source of interest rate inertia. For example, after a non-monetary policy shock, the subsequent dynamics of the economy will depend on the endogenous response of monetary policy-makers. Hence, knowing whether interest-rate smoothing is an inherent property of the policy-making process will be an important component of correctly forecasting the dynamic response of the economy to non-monetary shocks. Second, the underlying parameters of DSGE models are effectively estimated by comparing their predicted impulse responses to those observed in the data. Understanding whether the conditional response of the economy to shocks is subject to policy inertia will therefore matter for the estimates of all parameters of the model, not just those related to the policy rule. Third, whether observed inertia in interest rates reflects interest rate smoothing or persistent 
shocks matters for determinacy issues in New Keynesian models with positive trend inflation (Coibion and Gorodnichenko 2011).

Despite the importance of this distinction in the reasons for persistent policy rates, it has received little attention in the literature, with most work simply assuming that interest rate smoothing is the underlying source of interest rate persistence. Some research has estimated Taylor rules that nest both interest smoothing and persistent shocks, but this methodology has consistently failed to reject either hypothesis. Rudebusch (2002), English et al. (2003), Gerlach-Kristen (2004) and Consolo and Favero (2009) all estimate Taylor rules using single-equation methods and report evidence for both motives, albeit to differing degrees. Carrillo et al. (2007) and Smets and Wouters (2007) estimate nested specifications within fully specified DSGE models and also find evidence for both explanations.

We contribute to this debate in several ways. First, we apply the historical Greenbook forecasts to estimate the Taylor rule conditional on the Federal Reserve's real-time information, as in Orphanides (2003) and Coibion and Gorodnichenko (2011). Like previous work, we find that it is difficult to empirically differentiate between interest smoothing and persistent shocks: different specifications of the Taylor rule estimated over different time periods can support both motives for the observed interest rate persistence. However, previous research restricted interest smoothing persistent shocks to first order autoregressive processes. By allowing for more general forms of each, we show that the data is much more informative about the underlying source of interest rate persistence than previously uncovered. Using information criteria to select across a wide set of nested specifications with higher order interest smoothing and persistent shocks, the data strongly support specifications with only interest smoothing, with two lags of interest rates being the preferred specification. In addition, we show that when one allows for second order interest smoothing in the Taylor rule, the autoregressive parameters in the error term either become insignificantly different from zero or are negative. Thus, persistent shocks do not appear to have materially contributed to the persistence of interest rates once one allows for a more general form of interest smoothing than commonly considered in the literature.

Our second contribution is to provide a new method to test the relative merit of the two hypotheses. The key insight is that while both interest smoothing and persistent monetary policy shocks can adequately account for the observed persistence in interest rates, they have different implications for the conditional response of interest rates to non-monetary policy shocks. Specifically, interest rate smoothing implies that an inertial policy response should be observable after any shock, whereas this should not be the case under persistent monetary shocks. With the latter, the extra persistence in interest rates should obtain only after monetary policy shocks. We exploit this distinction to assess the relative merit of the two hypotheses by identifying the conditional response of policymakers to non-monetary policy shocks. Specifically, we employ an instrumental variables strategy in which our instruments are 
exogenous non-monetary policy shocks, including technology shocks, oil supply shocks, news shocks and fiscal shocks. These instruments serve to identify historical innovations to the Federal Reserve's forecasts of macroeconomic conditions driven by shocks other than monetary policy. As a result, they allow us to assess whether policy inertia is present in response to these shocks, a finding confirmed in the data. All of the estimates of interest smoothing are high, close to those obtained under OLS, and statistically significant at standard levels. Hence, this alternative approach also strongly supports the interest rate smoothing motive.

Our third contribution is to revisit the primary source of support for the persistent shocks explanation, namely the evidence provided by Rudebusch (2002) that future interest rate changes are largely unpredicted by financial market participants. His key insight was that if policy inertia is as high as implied by typical Taylor rule estimates, then interest rate changes two to three quarters in the future should be fairly predictable. Contrary to this, he documents little predictability of interest rates at these horizons by financial market participants using Eurodollar futures and we present similar evidence using professional forecasts of future short term interest rate changes. However, there are several factors that could make it difficult for private agents to precisely forecast future interest rate decisions even if policy inertia were strong. First, there could be uncertainty on the part of private agents about the exact form of the policy rule, such as whether the central bank responds to the output gap or output growth, what measure of inflation it focuses on, or whether policy inertia is important. Second, private agents typically have a more restricted information set than the Federal Reserve. Furthermore, even with the same information, agents may use different models than the staff of the Fed to formulate their forecasts. Romer and Romer (2000) document that Greenbook forecasts systematically outperform professional forecasters, which indicates that the Fed either has access to superior information about the economy or is more successful in converting that information into accurate forecasts. This informational asymmetry between monetary policymakers and the private sector provides a potential alternative explanation for the inability of private sector agents to correctly forecast future policy changes.

In light of these factors, we assess how well the staff members of the Fed are able to predict future interest rate changes. Specifically, we employ the assumptions made by the staff about future Federal Funds Rates and other short-term interest rates in generating the Greenbook forecasts as proxies for their expectations of future interest rates. While these need not represent the staff's unconditional best forecasts of future interest rates, they can provide a lower bound on the predictability of future interest rates changes by members of the Federal Reserve. And unlike the forecasts of private agents, internal forecasters at the Fed are more likely to correctly identify the policy rule and employ the same information as that embodied in the rest of the Greenbook forecasts. Consistent with this interpretation, we find that the Greenbook assumptions about the path of future interest rates can predict a larger fraction 
of future interest rate changes (both Fed Funds Rate and 3-month Tbill rate) than private sector forecasts, and that these forecasts are unbiased even at two and three quarter forecasting horizons, unlike private sector forecasts. Thus, this evidence indicates that future interest rate changes are predictable by internal members of the Fed, consistent with policy inertia, and that the inability of private agents to forecast interest rates as well as the Fed likely reflects informational constraints.

Finally, we consider the broader possibility that the excess persistence observed in interest rates relative to the predictions of simple Taylor rules reflects responses of the Federal Reserve to factors other than those explicitly included in the Taylor rule. Controlling for different measures of financial market conditions or revisions in the Fed's forecasts does not alter the estimated degree of interest smoothing. Another possibility is that the missing persistence could stem from a time-varying inflation target. Using different target inflation measures from Cogley et al. (2010), Ireland (2007) and Coibion and Gorodnichenko (2011), we find that the estimated degree of interest smoothing is unchanged while the role of persistent policy shocks is diminished. We also document that the persistence in policy shocks disappears after we incorporate into the Taylor rule the difference between Greenbook and private consensus forecasts. This suggests that the serial correlation in policy shocks may reflect informational flows between agents, such as if the central bank tries to utilize information in private forecasts or takes into account the fact that private forecasters try to learn about the central bank's information set from its policy actions or announcements.

The paper is organized as follows. Section 2 presents preliminary evidence on the performance of estimated Taylor rules assuming either interest rate smoothing or persistent shocks and illustrates how simple nested specifications do not convincingly differentiate between the two in the data. Section 3 considers more general forms of interest smoothing and persistent shocks and documents that interest rate smoothing is strongly preferred to persistent shocks once one allows for higher order descriptions of each process. Section 4 proposes and applies an instrumental variable procedure to assess the support for the two explanations of interest rate persistence while section 5 presents new evidence on the predictability of interest rate changes by private agents versus Federal Reserve forecasts. Section 6 considers the possibility of other factors being responsible for the persistence in interest rates. Finally, section 7 concludes.

\section{Interest Rate Smoothing vs. Persistent Monetary Policy Shocks}

In this section, we first consider simple versions of Taylor rules with interest rate smoothing and/or persistent monetary policy shocks using real-time measures of the Federal Reserve's forecasts of macroeconomic conditions. Second, we provide results using more general empirical specifications of both motivations for the persistence of interest rates. 


\subsection{Baseline Evidence on the Sources of Persistent Interest Rate Changes}

Since Taylor (1993), macroeconomists have relied on simple interest rate reaction functions to characterize the endogenous response of monetary policy-makers to economic fluctuations. While early work assumed that policy-makers respond to contemporaneous inflation and output gaps, more recent work has emphasized the importance of controlling for the real-time expectations of the central bank (Orphanides (2003), Coibion and Gorodnichenko (2011)). In this spirit, we consider the following baseline specification for monetary policy-makers' desired interest rate $\left(i_{t}^{*}\right)$

$$
i_{t}^{*}=c+\phi_{\pi} E_{t} \pi_{t+h}+\phi_{d y} E_{t} d y_{t+h}+\phi_{x} E_{t} x_{t+h}+u_{t}
$$

where $E$ denotes the central bank's forecast of macroeconomic variables, $\pi$ is inflation, $d y$ is the growth rate of output, and $x$ is the output gap. The rule departs from the classical Taylor (1993) specification in that it allows for responses to both the output gap and the growth rate of output as in Ireland (2004). The rule also allows for the central bank to respond to the forecast of future macroeconomic variables (horizon $h$ ), consistent with the notion that monetary policy changes take time to affect the economy so policymakers should be forward-looking in their policy decisions.

Estimating this rule by OLS from 1987Q4 until 2004Q4 (the Greenspan era) using the Greenbook forecasts prepared by the staff of the Federal Reserve before each FOMC meeting and the target Federal Funds Rate (FFR) for the interest rate yields

$$
\begin{gathered}
i_{t}=\underset{(0.50)}{1.06}+\underset{(0.14)}{1.76} E_{t} \pi_{t+2, t+1}-\underset{(0.09)}{0.11} E_{t} d y_{t}+\underset{(0.07)}{0.64 E_{t} x_{t}+u_{t}} \\
\sigma_{u}=0.75, \quad \bar{R}^{2}=0.89
\end{gathered}
$$

where Newey-West HAC standard errors are in parentheses. ${ }^{1}$ As emphasized by Taylor (1993), a simple specification such as this can account for much of the policy changes over this time period, with an $R^{2}$ of nearly $90 \%$. The estimated coefficients on expected inflation and the output gap are also close to those posited by Taylor (1993) despite the longer sample, the use of real-time data, and the different forecasting horizons. Figure 1 plots the actual time path of the target FFR over this time period, the predicted time path from the estimated reaction function, as well as the residuals from the regression, illustrating how well the Taylor rule can account for historical policy changes over this time period. However, the predictions of the Taylor rule are noticeably more volatile than actual interest rates: the average size of the predicted change in interest rates (in absolute value) is approximately sixty percent larger than actual quarterly changes in interest rates (57bp to $35 \mathrm{bp}$ ). Actual interest rates are also significantly more

\footnotetext{
${ }^{1}$ For all quarterly estimates of the Taylor rule, we use data from the meeting closest to the middle of each quarter. The choice of forecasting horizons is motivated by results in Coibion and Gorodnichenko (2011). We present additional results using alternative forecasting horizons and data at the frequency of FOMC meetings in later sections.
} 
persistent than predicted interest rates (AR(1) parameter of 0.98 versus 0.93 ). Finally, the residuals are serially correlated: the Durbin-Watson statistic is well under 1 and we can reject the null of no serial correlation of the residuals at standard levels.

The often-noted gradualism in actual interest rate targets has led many to adopt an alternative representation of monetary policy actions, in which the actual interest rate is a weighted average of the current desired rate and the previous period's interest rate:

$$
i_{t}=\rho_{i} i_{t-1}+\left(1-\rho_{i}\right) i_{t}^{*}
$$

where $\rho_{i}$ is the degree of interest rate smoothing. This type of inertia in monetary policy implies that central bankers will move interest rates toward their desired levels in a sequence of steps rather than in an immediate fashion as predicted by the baseline Taylor rule. Estimating this equation by OLS using the same data and time period as before yields

$$
\begin{gathered}
i_{t}=-0.57+\underset{(0.16)}{(0.05)} E_{t} \pi_{t+2, t+1}+\underset{(0.03)}{0.18} E_{t} d y_{t}+\underset{(0.02)}{0.14} E_{t} x_{t}+0.82 i_{t-1}+u_{t} \\
\sigma_{u}=0.26, \quad \bar{R}^{2}=0.99
\end{gathered}
$$

The estimated degree of interest rate smoothing of 0.82 is similar to those found in the literature, such as Clarida et al. (2000), and points to a very significant degree of policy inertia. Allowing for interest smoothing raises the ability of the specification to account for historical policy changes by a significant amount, with the $R^{2}$ rising to $99 \%$. Furthermore, allowing for interest smoothing eliminates much of the serial correlation in the residuals. For these reasons, interest smoothing has become a central feature of how monetary policy rules are characterized in modern macroeconomic models that play an increasingly important role in policy analysis.

An alternative explanation for the apparent inertia in interest rates suggested by Rudebusch (2002) is that it reflects persistent monetary policy shocks (or persistent deviations from the Taylor rule) rather than policy inertia. Under this interpretation, policy follows the Taylor rule in equation (1) but the shocks to the interest rate follow a persistent process such as

$$
u_{t}=\rho_{u} u_{t-1}+\varepsilon_{t}
$$

Applying the same data and time sample, we re-estimate equation (1) allowing for AR(1) errors and find

$$
\begin{gathered}
i_{t}=-1.91+\underset{(4.38)(0.11)}{0.28} E_{t} \pi_{t+1}-\underset{(0.03)}{0.05} E_{t} d y_{t}+\underset{(0.11)}{0.47} E_{t} x_{t}+u_{t}, \quad u_{t}=\underset{(0.03)}{0.98} u_{t-1}+\varepsilon_{t} \\
\sigma_{u}=0.39, \quad \bar{R}^{2}=0.97
\end{gathered}
$$

As with the specification under interest smoothing, we find strong evidence for extra persistence in interest rates, in this case measured by an autoregressive parameter of 0.98 for the error term. Allowing for persistent errors also significantly improves the fit of the empirical specification, with the $R^{2}$ rising to $97 \%$, and eliminates much of the serial correlation in the error $\varepsilon_{t}$. 
Figure 2 plots the actual target Federal Funds Rate over this time period as well the predicted levels from the specifications with either interest-smoothing or persistent shocks. As can readily be seen, the two specifications are nearly indistinguishable to the naked eye. Thus, both interest rate smoothing and persistent monetary policy shocks are able account for the excessive volatility of interest rate changes predicted by the baseline Taylor rule, improve the fit of the empirical reaction function, and control for much of the observed persistent deviations of actual interest rates from the predicted rates of the baseline Taylor rule. Yet determining whether the persistence of interest rates reflects interest rate smoothing or persistent shocks is a crucial determinant for interpreting the historical experience and forecasting future policy actions.

\subsection{The Limited Informativeness of Nested Specifications}

Because both approaches appear to fit the data so well, empirically determining the relative importance of interest rate smoothing and persistent shocks has been challenging. Rudebusch (2002) proposes a nested specification

$$
i_{t}=c+\phi_{\pi} E_{t} \pi_{t+h}+\phi_{d y} E_{t} d y_{t+h}+\phi_{x} E_{t} x_{t+h}+\rho_{i} i_{t-1}+u_{t}, \quad u_{t}=\rho_{u} u_{t-1}+\varepsilon_{t}
$$

but finds that the data are not sufficiently informative to reject either hypothesis and that small changes to the time period under consideration can lead to evidence that favors either hypothesis. Subsequent work using this approach has yielded similar results. English et al. (2003) find that both serially correlated shocks and interest rate smoothing are important, while Gerlach-Kristen (2004) similarly finds a role for both mechanisms but indicates that interest smoothing appears to be less important than suggested by the previous literature. Carrillo et al. (2007) use a DSGE model to estimate the Taylor rule and again document evidence for both mechanisms, but like Gerlach-Kristen, they argue that serially correlated shocks significantly reduce the importance of policy inertia.

One limitation common to each of these studies is their reliance on ex-post data rather than the ex-ante expectations of the Federal Reserve. As emphasized by Orphanides (2003), controlling for the real-time information available to central bankers, particularly in terms of measurements of the output gap, can significantly affect the historical interpretation of policy decisions. As a result, we estimate nested specifications, with results reported in Table 1. The point estimate for the degree of interest rate smoothing is 0.81 , almost identical to the original specification without persistent shocks, and is statistically significantly different from zero. The coefficient on the persistence of monetary policy shocks, however, is now much lower at 0.46 but remains statistically different from zero. Hence, conditional on the Federal Reserve's real-time information set, the data favors the interest smoothing motive over the persistent shock interpretation, but does not unambiguously reject either specification. 
Thus, like much of the previous literature, we find that a simple nested specification cannot overwhelmingly differentiate between the two explanations.

Table 1 presents additional results of the nested Taylor rule using different specifications of the Taylor rule. For example, using the Greenbook forecast of inflation in the next quarter rather than in the next two quarters (column 2) does not qualitatively affect the results. However, as noted by Rudebusch (2002), the results of the nested specifications are generally not very robust. For example, assuming that the central bank responds to the forecast of the current quarter's inflation rate (column 5), the coefficient on interest smoothing declines to 0.70 while the persistence of monetary policy shocks is now estimated to be 0.89 . Thus, this specification points to a stronger role for persistent shocks, although both the AIC and SIC indicate that our baseline specification is statistically preferred to one in which the central bank is assumed to respond to contemporaneous inflation. Similarly, allowing for a response to expected output growth in the next quarter rather than the current quarter or eliminating the response to output growth altogether (columns 3 and 4) leads to higher point estimates of the persistence of monetary policy shocks. In all cases, we can reject the null of either interest smoothing or persistent shocks being the sole mechanism that accounts for the excess persistence in interest rates observed in the data.

Table 2 presents additional results from estimating our preferred specification of the Taylor rule over different time periods. First, if we restrict the time sample to end in 1999Q4, as in Rudebusch (2002), the results are almost identical: we find evidence for both interest smoothing and persistent shocks, although the coefficient on interest smoothing is much larger than the estimated persistence of the shocks. Extending the sample back to 1983Q1 strengthens the case for interest-smoothing, as the estimated persistence of monetary policy shocks falls and becomes insignificantly different from zero. Table 2 also includes results from estimating the baseline Taylor rule at the frequency of FOMC meetings, approximately every six weeks over this time period, rather than at the quarterly frequency. Over the Greenspan period, the results point more strongly toward the interest smoothing motive: the coefficients on lagged interest rates are around 0.90 and statistically significant at conventional levels, while the estimated persistence of monetary shocks is small and insignificantly different from zero. Using the entire post-1982 era yields slightly more mixed evidence, with the autoregressive parameter governing the dynamics of the error term becoming positive and statistically significant at the $10 \%$ level. Thus, across specifications and time periods, the results are remarkably mixed: while most of the specifications point to an important role for policy inertia, it is difficult to systematically rule out persistent shocks as an alternative explanation for the interest rate inertia apparent in the data. 


\section{Generalized Specifications of Interest Rate Smoothing and Persistent Shocks}

While the evidence from the previous section suggests that interest rate smoothing is a somewhat more potent explanation for the persistence of interest rate changes observed in the data than persistent shocks, the evidence is mixed at best as minor variations in the specification of the Taylor rule can move the relative importance of the two mechanisms substantially. However, an important caveat is that, like previous work, we have only considered the simplest forms of each specification, namely first-order autoregressive specifications for both interest rate smoothing and persistent monetary policy shocks. On the other hand, other work on estimating Taylor rules has identified evidence that interest smoothing could be higher order: Coibion and Gorodnichenko (2011), for example, find that interest smoothing is best characterized as a second order autoregressive process. In the same spirit, there is no a priori reason to suspect that the persistence of monetary policy shocks, or more broadly deviations from the Taylor rule, is best characterized as a first order autoregressive process. In this section, we allow for higher order processes for both interest smoothing and persistent shocks, i.e. we consider empirical specifications of the form

$$
\begin{aligned}
& i_{t}=c+\phi_{\pi} E_{t} \pi_{t+h}+\phi_{d y} E_{t} d y_{t+h}+\phi_{x} E_{t} x_{t+h}+\sum_{i=1}^{I} \rho_{i} i_{t-i}+u_{t}, \\
& u_{t}=\sum_{j=1}^{J} \rho_{u, j} u_{t-j}+\varepsilon_{t} .
\end{aligned}
$$

We assess the relative merit of interest rate smoothing and persistent shocks using two methods. First, we compute the BIC criteria associated with the same specifications of the desired interest rate as in the previous section, but now allowing both $I$ and $J$ to range from zero to four. Thus, we include specifications with only interest-smoothing, only persistent shocks, neither, and a variety of specifications with both interest-smoothing and persistent shocks. As a result, this kind of model-selection criterion can shed some light on the relative merit of the two approaches while allowing for more general forms of both interest smoothing and persistent shocks than in the previous section. The results are presented in Table 3 for different time periods using data at both the quarterly frequency and the FOMC meetings frequency. The results strongly favor the interest smoothing motive: all but one of the specifications of the Taylor rule estimated at the quarterly frequency achieve the lowest BIC with two lags of the interest rate and no persistence in monetary policy shocks. The one exception, when the central bank is assumed not to respond to output growth, yields a specification with one lag of the interest rate and first-order autoregressive shocks. However, the BIC for this specification of the Taylor rule is substantially higher than for versions of the Taylor rule which include output growth. This finding is consistent with Coibion and Gorodnichenko (2011) in that the rule which is consistently preferred by the data includes a response to expected inflation over the next two quarters, expected output growth and the output gap in the current quarter, and two lags of the interest rate. The results using data at the frequency of the FOMC meetings 
are similar. Most of the preferred specifications since 1987 include no persistent shocks. Only when the time period is extended to 1983 do we find some evidence for persistent shocks.

As a second approach, we present results from estimating equation (3) assuming two lags of the interest rate and a second order autoregressive process for monetary policy shocks for each of the Taylor rule specifications considered before over the time period 1987Q4 to 2004Q4. These results are in Table 4. Consistent with the results in Table 3, both interest rate lags are statistically significant for each of the Taylor rule specifications, and the sum of the coefficients is between 0.75 and 0.95 so that the degree of interest smoothing is always high. On the other hand, the first autoregressive parameter for shock persistence is never statistically different from zero, while the second autoregressive parameter, when different from zero, is negative. ${ }^{2}$ Hence, once we allow for higher order interest smoothing, the evidence robustly favors the interest smoothing motive.

\section{Conditional Monetary Policy Reaction Functions}

While the nested specifications lend greater support to the interest rate smoothing motive than previously noted, we want to consider alternative approaches which might shed light more directly on what the underlying source of persistent interest rate changes is. In this section, we consider a novel test of the two hypotheses. If the persistence of interest rate changes observed in the data is primarily driven by persistent monetary policy shocks, then the conditional response of interest rates should be slow after monetary policy shocks but not other macroeconomic shocks. Intuitively, interest rate smoothing implies policy inertia regardless of the source of the underlying fluctuations, whereas the persistent monetary policy shocks explanation imposes additional interest rate persistence in response only to monetary policy shocks.

To see this more formally, note that after log-linearization and solving for the rational expectations solution, variables $(z)$ in macroeconomic models can generically be expressed in MA $(\infty)$ form

$$
E_{t} z_{t+h}=\sum_{i=0}^{\infty} \sum_{s=1}^{S} \delta_{i, s} \varepsilon_{s, t-i}
$$

where $i$ refers to periods and $\varepsilon$ refers to structural shocks denoted by $s$, here ordered numerically from 1 to $S$. We can then define the component of $z$ driven by monetary policy shocks as

$$
E_{t} z_{t+h}^{m p}=\sum_{i=0}^{\infty} \delta_{i, m p} \varepsilon_{m p, t-i}
$$

and the component driven by all other shocks as

$$
E_{t} z_{t+h}^{-m p}=E_{t} z_{t+h}-E_{t} z_{t+h}^{m p}
$$

\footnotetext{
${ }^{2}$ Similar results obtain using higher order autoregressive specifications of the error term: the coefficients are either insignificantly different from zero or negative.
} 
Assuming structural shocks are uncorrelated with each other and across time, then the component of $z$ driven by exogenous monetary policy shocks and that driven by all other shocks will be uncorrelated as well. The desired interest rate can then be expressed as

$$
i_{t}^{*}=i_{t}^{-m p}+i_{t}^{m p}+u_{t}
$$

where $i_{t}^{m p} \equiv \phi_{\pi} E_{t} \pi_{t+j}^{m p}+\phi_{d y} E_{t} d y_{t}^{m p}+\phi_{x} E_{t} x_{t}^{m p}$ and similarly for $i_{t}^{-m p}$. Equation (7) decomposes changes in the desired interest rate into two components capturing the endogenous responses of monetary policy to macroeconomic fluctuations $\left(i_{t}^{-m p}\right.$ for non-monetary policy shock driven fluctuations and $i_{t}^{m p}$ for monetary-policy driven fluctuations) and the exogenous shocks to interest rates $(u)$.

This decomposition provides an alternative approach to assess the source of the interest rate persistence in the data. In the case with persistent monetary policy shocks but no interest smoothing, the endogenous response of interest rates to non-monetary policy shocks should not be subject to excess persistence, whereas under interest smoothing, the need for additional persistence should be apparent in response to non-monetary policy shocks. This insight can be applied to the analysis of the Taylor rule if one can identify variations in the endogenous response of interest rates to shocks other than monetary policy. To do so, we propose to use instrumental variables estimation of the Taylor rule, using exogenous structural shocks as instruments. The latter will be uncorrelated with monetary policy shocks and the endogenous response of interest rates to policy shocks $\left(i_{t}^{m p}+u_{t}\right)$, thereby allowing us to assess whether interest smoothing is present in the face of non-monetary policy driven fluctuations in macroeconomic conditions. $^{3}$

To apply this method to historical monetary policy, we estimate equation (3) using instrumental variables. Specifically, our instruments are two lags of permanent technology shocks from Gali (1999), purified innovations to the Solow residual as in Basu, Fernald and Kimball (2006), news shocks as in Beaudry and Portier (2006), oil supply shocks as identified by Kilian (2009), and tax shocks from Romer and Romer (2010). Results from applying this procedure to different time samples at the quarterly frequency are presented in Table 5. ${ }^{4}$ In each case, the coefficient on interest smoothing is high, on the order of 0.8 , and statistically different from zero. Hence, inertia in policy actions exists in response to variations in macroeconomic conditions arising from non-monetary policy shocks. This result indicates that interest-rate smoothing is likely not simply reflecting persistent monetary policy shocks, but rather reflects a fundamental component of the policy process of the Federal Reserve, consistent with the results using nested specifications of interest smoothing and persistent shocks.

\footnotetext{
${ }^{3}$ We verified in Monte Carlo simulations that IV estimation of the Taylor rule using exogenous shocks as instruments could correctly identify the absence of interest smoothing when the data generating process is driven entirely by persistent shocks. Results available upon request.

${ }^{4}$ We do not present equivalent results at the FOMC meetings frequency because most of the shocks used as instruments are only available at the quarterly frequency.
} 


\section{Predictability of Interest Rate Changes}

While the evidence from the analysis of Taylor rules using real-time data clearly favors the interestsmoothing explanation, Rudebusch (2002) suggests an alternative metric to assess the two explanations which he argues is consistent with the persistent shocks interpretation. His insight is that if policy was driven by interest rate smoothing, then interest rate changes should be quite predictable. Using futures markets for interest rates, he finds that markets are quantitatively unable to predict future interest rate changes at a two to three quarter ahead horizon, a result that he argues is difficult to reconcile with policy inertia.

The specific test employed by Rudebusch (2002) consists of the following empirical specification:

$$
i_{t+h}-i_{t+h-1}=c+\beta\left[E D_{t, t+h}-E D_{t, t+h-1}\right]+\varepsilon_{t}
$$

where $E D_{t, t+h}$ is the time $t$ expectation of the interest rate on Eurodollar deposits during quarter $t+h$. Eurodollar futures have been the trading vehicle of choice for hedging short-run interest rate movements since the mid-1980s and therefore provide one measure of financial market participants' forecasts of future interest rate changes. Assuming a constant risk premium (incorporated in the intercept), efficient markets and full information on the part of market participants imply a null hypothesis of $\beta=1$. Furthermore, if interest rate decisions exhibit significant inertia, then market forecasts should be able to predict a non-trivial component of future interest rate changes.

In Table 6, we reproduce the original results of Rudebusch (2002) over the time sample of 1987Q4 to 1999Q4. At the one quarter ahead forecasting horizon, $\beta$ is not different from one but significantly greater than zero. With an $R^{2}$ of more than $50 \%$, this indicates that markets are able to predict short-term changes in the FFR quite well. However, as emphasized by Rudebusch (2002), these results rapidly deteriorate at longer forecasting horizons. At the two and three quarter forecasting horizons, the null of $\beta=1$ can be rejected and the $R^{2}$ falls to $11 \%$ and $3 \%$ respectively. Using simulations from a New Keynesian model with a Taylor rule containing interest smoothing, Rudebusch finds that such a low predictability of future interest rate changes is an unlikely outcome, i.e. outside the $95 \%$ confidence intervals of $R^{2}$ from the simulations, for levels of interest smoothing like those estimated in the data. Thus, the low predictability of interest rates at the two and three quarter forecasting horizons suggests that policy inertia may not be the key driving source of interest rate persistence in the data.

On the other hand, there are several factors which could, even in the presence of policy inertia, lead financial market futures to be poor predictors of subsequent interest rates. One feature, emphasized by Rudebusch (2002), is the possibility of a time-varying risk premium. In addition, financial market participants could be unsure of what the policy rule actually is, e.g. does the Fed respond to the output gap 
or output growth, what is the preferred measure of inflation, is there policy inertia in the rule, etc... Third, private agents could have less information than the Federal Reserve. Evidence of this is documented by Romer and Romer (2000) in the case of professional forecasters: they find that Greenbook forecasts systematically outperform professional forecasts of inflation. Ang et al. (2007) show that professional forecasts of inflation dominate asset-price based forecasts of inflation, so Greenbook forecasts likely have a significant informational advantage over financial market forecasts. Finally, agents could be unsure about the underlying model used by the Federal Reserve to translate its information set into forecasts of macroeconomic variables. In this case, even if agents had the same information about current and past macroeconomic conditions, this might lead them to generate different forecasts than the Federal Reserve, which would translate into additional interest rate prediction errors. As a result, the inability of financial market participants to forecast future interest rate changes could reflect a variety of factors other than a lack of policy inertia.

To assess the importance of these factors, we use the forecasts of the FFR embodied in the Greenbook forecasts of the Federal Reserve. The staff of the Board of Governors makes assumptions about the future path of the FFR in generating forecasts of other macroeconomic variables, which can be interpreted as forecasts of future policy actions. ${ }^{5}$ Because these forecasts are generated at the same time as the forecasts of other macroeconomic variables in the Greenbooks, they should embed consistent assumptions about the policy rule, consistent information sets, and a consistent model used to convert information into forecasts. In short, these forecasts of the FFR could possess much more information about the predictability of interest rates driven by policy inertia than market forecasts. Figure 3 plots the historical FFR and selected forecasts from both financial markets and the Greenbooks (from the first quarter of each year). Overall, forecasts from the Greenbooks seem to dominate other forecasts. Only since 2000 do the financial market forecasts appear to do nearly as well as Greenbook forecasts.

Table 6 shows the estimated parameters from estimating equation (8) using the Greenbook assumptions about future interest rates in lieu of financial market forecasts over the same time sample. The results are in stark contrast to those obtained using financial market forecasts. Even at the two and three quarter forecasting horizons, the point estimates of $\beta$ are very close to one and statistically different from zero at standard levels. The $R^{2}$ of $20 \%$ and $12 \%$ at the two and three quarter ahead forecasting horizons are also significantly higher than obtained using financial market forecasts and lie within the 95\% confidence intervals constructed by Rudebusch (2002) that one would expect to find in the presence of substantial policy inertia. This result implies that future interest rate changes are in fact approximately as predictable as one would expect under significant interest rate smoothing, conditional on having

\footnotetext{
${ }^{5}$ Note that these assumptions about the future path of the FFR need not be the unconditional best forecast of future policy actions by the staff of the Fed, and therefore may still underestimate the predictability of future interest rate changes.
} 
sufficient information about the policy rule and macroeconomic conditions. The inability of financial market forecasts to predict future interest rate changes is thus likely to primarily reflect variations in the risk premium or informational constraints, not an absence of inertia in interest rate setting decisions.

We also produce analogous results for changes in 3-month T-Bill rates using the Greenbook forecasts of the latter as well as the median forecasts from the Survey of Professional Forecasters. ${ }^{6}$ Professional forecasts present an additional source of information about the ability of private agents to forecast future policy changes and are typically of high quality: Ang et al. (2007) document that professional forecasts of inflation outperform most time series models and financial market forecasts. Figure 3 plots the 3-month T-Bill rate, along with forecasts from professional forecasters and Greenbooks. While the SPF appear to do better than financial market forecasts, the Greenbooks still appear to give better forecasts of the path of future interest rates. The results from estimating equation (8) using these data, presented in Table 6, are qualitatively similar to those using FFR forecasts. Professional forecasters, like financial market participants, are unable to predict interest rate changes much beyond the one quarter ahead forecasting horizon, while the Greenbook forecasts continue to yield point estimates of $\beta$ which are significantly greater than zero and close to one, with $R^{2}$, s of the same order as that obtained using Greenbook forecasts of the FFR.

Table 6 also presents estimates of equation (8) for each type of forecast for the extended time sample of 1987Q4 to 2004Q4. The results using the Greenbook forecasts are qualitatively unchanged, with estimates of $\beta$ remaining close to one at all forecasting horizons and $R^{2}$ of similar, if slightly lower, magnitudes. Results using the Survey of Professional Forecasters are also qualitatively unchanged, with these agents being significantly worse at forecasting interest rate changes than the staff of the Federal Reserve. The one noticeable difference using this extended time sample is the improved performance of financial market forecasts: the null of $\beta=1$ cannot be rejected at any of the forecasting horizons and the $R^{2}$ s are noticeably larger, particularly at the one and two quarter forecasting horizons. For the latter, financial market forecasts even outperform the Greenbook forecasts and the fraction of interest rate changes predicted, at $20 \%$, lies well within the median $95 \%$ confidence interval from the simulations of Rudebusch in the presence of significant interest smoothing. This is consistent with Figure 3, which shows that financial markets correctly predicted much of the decline in interest rates during 2000. In short, we document stronger evidence of interest rate predictability than previously found, particularly when using the Greenbook forecasts of interest rates. This suggests that the previously identified poor performance of private forecasts of future interest rates may be largely driven by informational constraints

\footnotetext{
${ }^{6}$ SPF forecasts of the Federal Funds Rate are not available over this time sample, which is why we use 3-month TBill rates instead.
} 
such as uncertainty about the policy rule and the superior forecasting ability of the central bank, and not by an absence of policy inertia.

\section{Omitted Variables and the Persistence of Interest Rates}

While much of the evidence strongly supports the interest smoothing motive over the persistent monetary policy shocks explanation of interest rate persistence, a broader interpretation of the latter is difficult to rule out. For example, Rudebusch $(2002,2006)$ suggests that the excess persistence in interest rates is most likely to come from historical responses of the central bank to factors not typically included in the Taylor rule. Credit conditions are one particularly prominent example of such an omitted factor likely to elicit a central bank response, and their exclusion from standard Taylor rules could give the appearance of either inertial policy or persistent shocks. Similarly, the gradual adjustment of the central bank's information set, and their need to adjust policy based on their revised estimates of the state of the economy, could point to either policy inertia or persistent shocks. In this section, we consider a variety of factors which, when omitted from the estimated reaction function of the central bank, could lead to the appearance of excessive interest rate persistence.

We first consider the role of credit and asset price conditions. These are particularly likely to have played an important historical role in affecting interest decisions. For example, the October 1987 stock market crash led the Federal Reserve to lower the effective FFR by fifty basis points between October $19^{\text {th }}$ and October $20^{\text {th }}$ and engage in a variety of other activities to maintain liquidity in financial markets (Carlson 2007). To assess whether credit and asset market conditions can account for either interest smoothing or persistent shocks, we consider estimates of equation (3) augmented with lagged measures of financial conditions using quarterly data from 1987Q4 to 2004Q4. We use three such measures: 1) the spread between Moody's Baa corporate bond rate and the ten-year U.S. treasury note, 2) the log of the quarterly average of the S\&P500 index, and 3) Bloom's (2009) measure of financial market uncertainty. Table 7 presents empirical estimates of our baseline Taylor rule allowing for two lags of interest smoothing, a second order autoregressive process for the error term, and our three measures of financial market conditions. All three measures are insignificantly different from zero and have no qualitative effects on interest smoothing and shock persistence. Thus, there is little evidence that systematic responses by the Federal Reserve to financial market conditions account for the persistence in interest rates in the data.

An alternative explanation could come from imperfect information on the part of the central bank. Because of lags in the release of data as well as data revisions, the Fed can revise its forecasts of the current state by significant amounts. Interest rate changes could therefore arise not just from changes in the central bank's expectations about future economic developments but also from revisions to its 
expectations about the current state. To assess whether this source of interest rate changes could account for the excess persistence in interest rates, we follow Romer and Romer (2004) and augment the baseline Taylor rule with revisions in the central bank's forecasts of inflation, output growth and the output gap. Results from this specification are in Table 7. As with financial market controls, we find no evidence of a systematic response to forecast revisions and controlling for these measures does not alter the relative importance of interest smoothing and persistent shocks.

A third possible explanation for the excess persistence in interest rates relative to simple Taylor rule predictions is persistent variation in the central bank's target rates of inflation, output gap and output growth. In the baseline specifications of the Taylor rule, each of these targets is assumed to be constant and integrated into the intercept of the regression. However, Boivin (2006), Kozicky and Tinsley (2009) and Coibion and Gorodnichenko (2011) estimate versions of the baseline Taylor rule with time-varying coefficients and document non-trivial changes in the intercept, and therefore in the targets of the FOMC. ${ }^{7}$ Kozicki and Tinsley (2009) and Coibion and Gorodnichenko (2011) further document that, controlling for time-variation in both the intercept and the response coefficients, the degree of interest-smoothing after the early 1980s has remained high, statistically significant, and stable. Since much of this time-variation in targets is likely to emanate from changes in the inflation target, we consider estimates of equation (3) in which we replace the measure of expected inflation with a measure of the expected deviation of inflation from a time-varying target. We employ three measures of the target rate of inflation: 1) Cogley et al.'s (2010) measure extracted from a VAR with drifting parameters and stochastic volatility; 2) Coibion and Gorodnichenko's (2011) measure extracted from Taylor rule estimates with drifting parameters; and 3) Ireland's (2007) measure constructed from an estimated New Keynesian DSGE model. Figure 4 plots these three measures of target inflation, which exhibit broadly similar patterns despite the different approaches employed to estimate them. By and large, we find that in this alternative specification of the policy reaction function the serial correlation in the error terms becomes less important and for two out of three measures statistically insignificant. The fit of this alternative specification is somewhat worse than the fit of the baseline specification which probably reflects the fact that these measures of the target inflation rate are constructed and may contain measurement errors. In any case, to the extent that these measures capture salient movements in the target inflation rate, these results support the hypothesis that serial correlation in the error term could be absorbing variation in the inflation target rate.

The final possibility that we consider is that the central bank responds not just to its expectations of current and future macroeconomic conditions but also to those of private sector agents. There are

\footnotetext{
${ }^{7}$ Time variation in the intercept can also reflect changes in the equilibrium real rate of interest, as in Trehan and Wu (2007).
} 
several reasons why the central bank might wish to pursue such policies. First, while the Federal Reserve's forecasts are typically superior to those of professional forecasters, as documented by Romer and Romer (2000), policy-makers may be concerned about the quality of their forecasts when they differ substantially from those of other agents. This could lead policymakers to respond less strongly to their own forecasts to hedge against the possibility that their forecasts are incorrect. As a result, this phenomenon could also account for why actual interest rates appear to be less volatile than interest rates predicted from a Taylor rule employing only Greenbook forecasts. Second, policymakers could be concerned about the effect of their decisions on the expectations of other agents. For example, if the central bank has superior information than private agents, then its interest rate decisions will reveal part of the central bank's information to the rest of the population and therefore alter their expectations, as considered in e.g. Walsh (2010). This could be potentially destabilizing: if the central bank is concerned about rising inflation but observes no movement in the private sector's expectations of inflation, it could be optimal on the part of the central bank to avoid raising interest rates too rapidly so that agents do not infer from the policy actions that the central bank is concerned about rising inflation, a result which could exacerbate inflationary pressures as higher private sector inflation expectations would increase wage and price pressures.

Figure 5 illustrates the deviations in the Greenbook forecasts from equivalent forecasts from professional forecasters in the Philadelphia Fed's Survey of Professional Forecasters for both inflation and output growth. In addition, Figure 5 includes the residuals from the simple Taylor rule with no smoothing or persistent shocks, i.e. equation (1) in section 2. There is a clear negative correlation between the Taylor rule residuals and the deviation of Greenbook inflation forecasts from professionals' inflation forecasts. The periods in 1989, 1995, 1998 and 2000-2001 when actual interest rates were above those predicted by the baseline Taylor rule all coincide with periods in which Greenbook forecasts of inflation were lower than professional forecasts of inflation, and the reverse pattern occurs in 1990, 1996, and late 2001 during which interest rates were below those predicted by the Taylor rule while professional forecasters were expecting lower inflation than staff members of the Fed's Board of Governors. The relationship between Taylor rule residuals and output growth forecast differentials may appear less systematic to the naked eye, but there are episodes where negative comovement is clear, such from 1991 to 1996 and again from 1998 to 2001.

We evaluate the statistical strength of these relationships by estimating equation (3) augmented with the difference between the Greenbook forecast of future inflation and that of professional forecasters in the Survey of Professional Forecasters, and the analogous measure for the difference in forecasts of contemporaneous output growth. We do not control for potential differences in the estimates of the output gap between the Fed and professional forecasters because no forecast of the output gap is available 
for the latter. The results, presented in Table 7, are consistent with the described mechanisms. The coefficients on both the inflation forecast and output growth forecast differentials are negative and statistically significant, indicating smaller interest rate changes when the Fed forecasts point to more expansionary and/or inflationary conditions than private sector forecasts. Furthermore, controlling for these informational elements eliminates the persistence of the errors: the coefficients on both autoregressive parameters are insignificantly different from zero. At the same time, the degree of interest smoothing is qualitatively unchanged. This suggests a novel potential explanation for deviations of actual interest rates from standard Taylor rule prescriptions. Understanding the basis for this systematic response of monetary policymakers to private agents' forecasts is an important topic for future research.

\section{Conclusion}

The way in which policymakers endogenously respond to economic fluctuations plays a key role in determining the dynamic effect of shocks to the economy. Understanding the historical contribution of endogenous policy reactions to economic fluctuations therefore requires a careful characterization of the nature of policy decisions and the rate at which policy changes occur. The gradual adjustment of interest rates by the Federal Reserve is one issue that has been a source of contention. We provide novel evidence using a variety of methods that consistently supports the notion that inertia in monetary policy actions has indeed been a fundamental, deliberate component of the decision-making process by monetary policy makers. More specifically, our evidence strongly favors interest-rate-smoothing theory over seriallycorrelated-policy-shocks theory as an explanation of highly persistent policy rates set by the Fed.

This result has several important implications. First, it should help guide forecasters in more accurately predicting the path of future interest rates. For example, the expected duration of near-zero interest rates and the pace at which interest rates will rise upon exiting the zero-bound hinge on the amount of monetary policy inertia. Second, assuming that policy inertia in interest rate decisions is likely to transfer to other monetary tools, the evidence provided in this paper indicates that the exit strategy with respect to tools other than interest rates is likely to be gradual, even if the economy recovers more rapidly than currently expected. Third, our results should help guide future research using DSGE models as to how best to formulate the endogenous response of monetary policy makers to endogenous economic fluctuations. 


\section{References}

Ang, Andrew, Geert Bekaert, and Min Wei, 2007. "Do macro variables, asset markets, or surveys forecast inflation better?" Journal of Monetary Economics 54(4), 1163-1212.

Basu, Susanto, John Fernald, and Miles Kimball, 2006. "Are Technology Improvements Contractionary?" American Economic Review 96(5), 1418-1448.

Beaudry, Paul, and Franck Portier, 2006. "News, Stock Prices and Economic Fluctuations," American Economic Review 96(4), 1293-1307.

Bloom, Nicholas, 2009. “The Impact of Uncertainty Shocks,” Econometrica 77(3), 623-685.

Carlson, Mark, 2007. "A Brief History of the 1987 Stock Market Crash with a Discussion of the Federal Reserve Response," Board of Governors of the Federal Reserve System Finance and Economics Discussion Series \#2007-13.

Carrillo, Julio, Patrick Feve, and Julien Matheron, 2007. "Monetary Policy Inertia or Persistent Shocks: A DSGE Analysis," International Journal of Central Banking 3(2), 1-38.

Clarida, Richard, Jordi Galí, and Mark Gertler, 2000. "Monetary Policy Rules and Macroeconomic Stability: Evidence and Some Theory," Quarterly Journal of Economics 115(1), 147-180.

Cogley, Timothy, Giorgio E. Primiceri, and Thomas J. Sargent, 2010. "Inflation-Gap Persistence in the U.S.," American Economic Journal: Macroeconomics 2(1), 43-69.

Coibion, Olivier, and Yuriy Gorodnichenko, 2011. "Monetary Policy, Trend Inflation and the Great Moderation: An Alternative Interpretation," American Economic Review 101(1).

Consolo, Agostino, and Carlo A. Favero, 2009. "Monetary policy inertia: More a fiction than a fact?" Journal of Monetary Economics 56(6), 900-906.

English, William B., William R. Nelson, and Brian P. Sack, 2003. "Interpreting the Significance of the Lagged Interest Rate in Estimated Monetary Policy Rules," Contributions to Macroeconomics 3(1), Article 5.

Gali, Jordi, 1999. "Technology, Employment, and the Business Cycle: Do Technology Shocks Explain Aggregate Fluctuations?" American Economic Review 89(1), 249-271.

Gerlach-Kristen, Petra, 2004. "Interest-rate Smoothing: Monetary Policy Inertia or Unobserved Variables?" Contribution to Macroeconomics 4(1) Article 3.

Ireland, Peter N., 2004. "Technology Shocks in the New Keynesian Model," Review of Economics and Statistics 86(4), 923-936.

Ireland, Peter N., 2007. "Changes in the Federal Reserve's Inflation Target: Causes and Consequences," Journal of Money, Credit, and Banking 39(8)б 1851-1882ю

Kilian, Lutz, 2009. "Not All Oil Price Shocks Are Alike: Disentangling Demand and Supply Shocks in the Crude Oil Market," American Economic Review 99(3), 1053-1069.

Kozicki, Sharon, and Peter A. Tinsley. 2009. "Perhaps the 1970s FOMC Did What It Said It Did," Journal of Monetary Economics 56(6), 842-855.

Levin, Andrew, Volker Wieland, and John C. Williams, 1999. "Robustness of Simple Monetary Policy Rules under Model Uncertainty," in John B. Taylor, ed. Monetary Policy Rules (Chicago University Press, Chicago) 263-299.

Orphanides, Athanasios, 2003. "Historical Monetary Policy Analysis and the Taylor Rule," Journal of Monetary Economics 50(5), 983-1022.

Romer, Christina, and David H. Romer, 2000. "Federal Reserve Information and the Behavior of Interest Rates," American Economic Review 90(3), 429-457.

Romer, Christina, and David H. Romer, 2000. "A New Measure of Monetary Shocks: Derivation and Implications," American Economic Review 94(4), 1055-1084.

Romer, Christina and David H. Romer, 2010. "The Macroeconomic Effects of Tax Changes: Estimates Based on a New Measure of Fiscal Shocks," American Economic Review 100(3), 763-801.

Rudebusch, Glenn D., 2002. "Term structure evidence on interest rate smoothing and monetary policy inertia," Journal of Monetary Economics 49(6), 1161-1187. 
Rudebusch, Glenn D., 2006. “Monetary Policy Inertia: Fact or Fiction?" International Journal of Central Banking 2(4), 85-135.

Smets, Frank R., and Raf Wouters, 2007. "Shocks and Frictions in U.S. Business Cycles: A Bayesian DSGE Approach," American Economic Review 97(3), 586-606.

Taylor, John B., 2003. "Discretion versus policy rules in practice," Carnegie-Rochester Conference Series on Public Policy 39, 195-214.

Trehan, Bharat, and Tao Wu, 2007. "Time-Varying Equilibrium Real Rates and Monetary Policy Analysis," Journal of Economic Dynamics and Control 31(5), 1584-1609.

Walsh, Carl E., 2010. "Transparency, the Opacity Bias, and Optimal Flexible Inflation Targeting," manuscript.

Woodford, Michael, 1999. "Optimal Monetary Policy Inertia," Journal of Monetary Economics 37(3), 573-605.

Woodford, Michael, 2003. Interest and Prices: Foundations of a Theory of Monetary Policy, Princeton: Princeton University Press. 
Figure 1: Target Federal Funds Rate and the Prediction of a Simple Taylor Rule

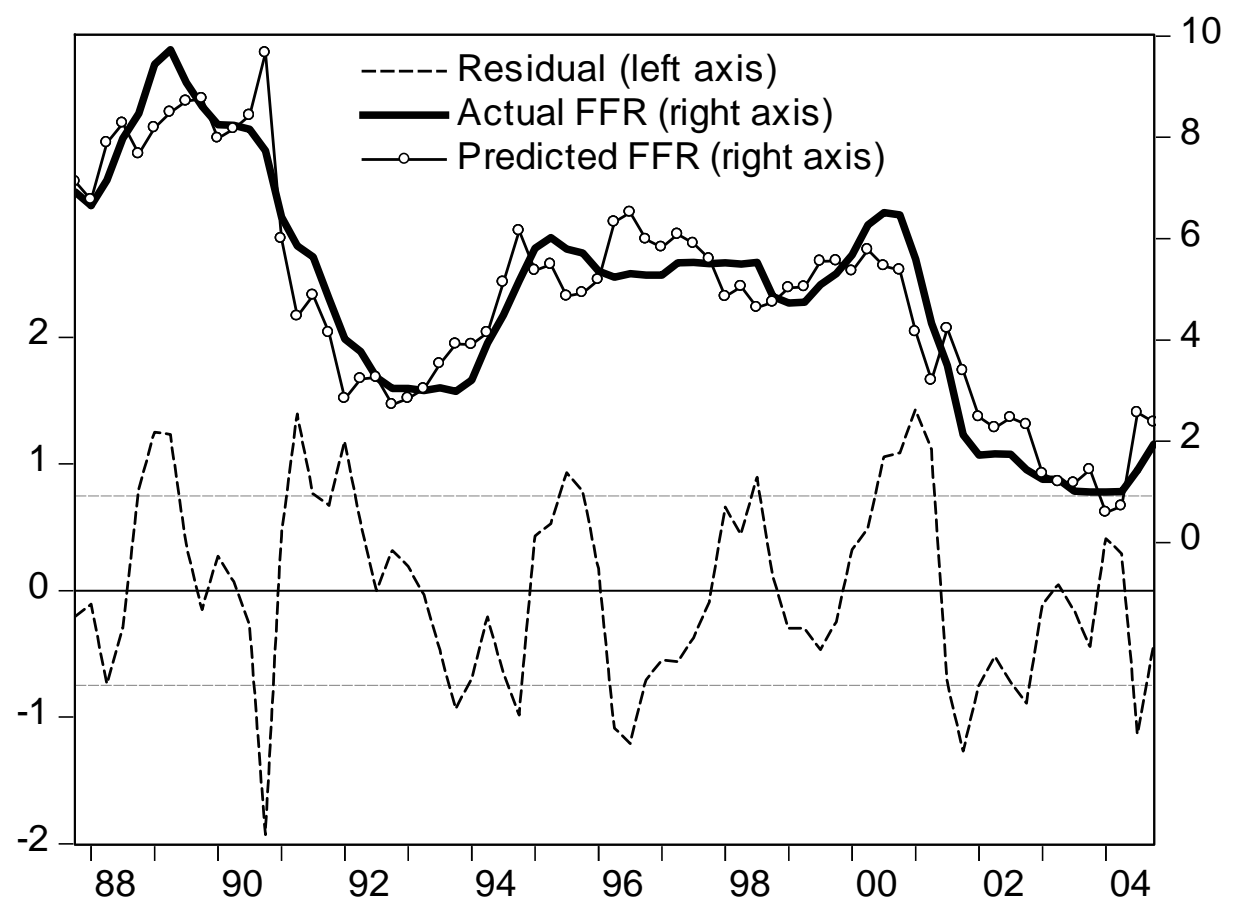

Note: The figure plots the actual target FFR, the predicted FFR from equation (1) in section 2, and the residuals of the regression. See section 2.1 for details. 
Figure 2: Target Federal Funds Rate and the Predictions of Augmented Taylor Rules

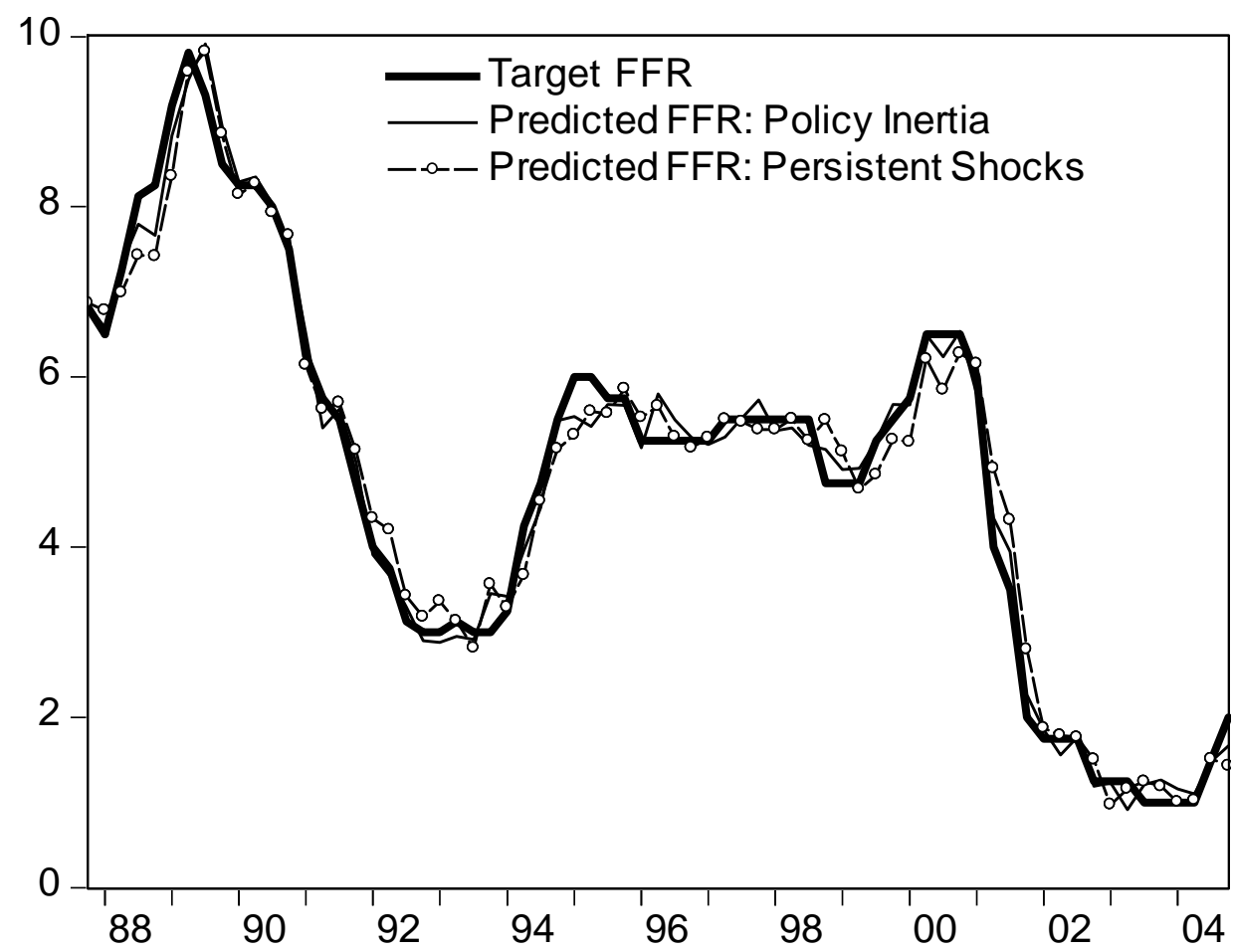

Note: The figure plots the actual target FFR and the predicted FFR's from estimating augmented versions of the Taylor rule including either interest smoothing (policy inertia) or persistent shocks. See section 2.1 for details. 
Figure 3: Interest Rate Forecasts of the Fed, Financial Markets, and Professional Forecasters

Panel A: Forecasts of the FFR from Financial Markets and Greenbooks

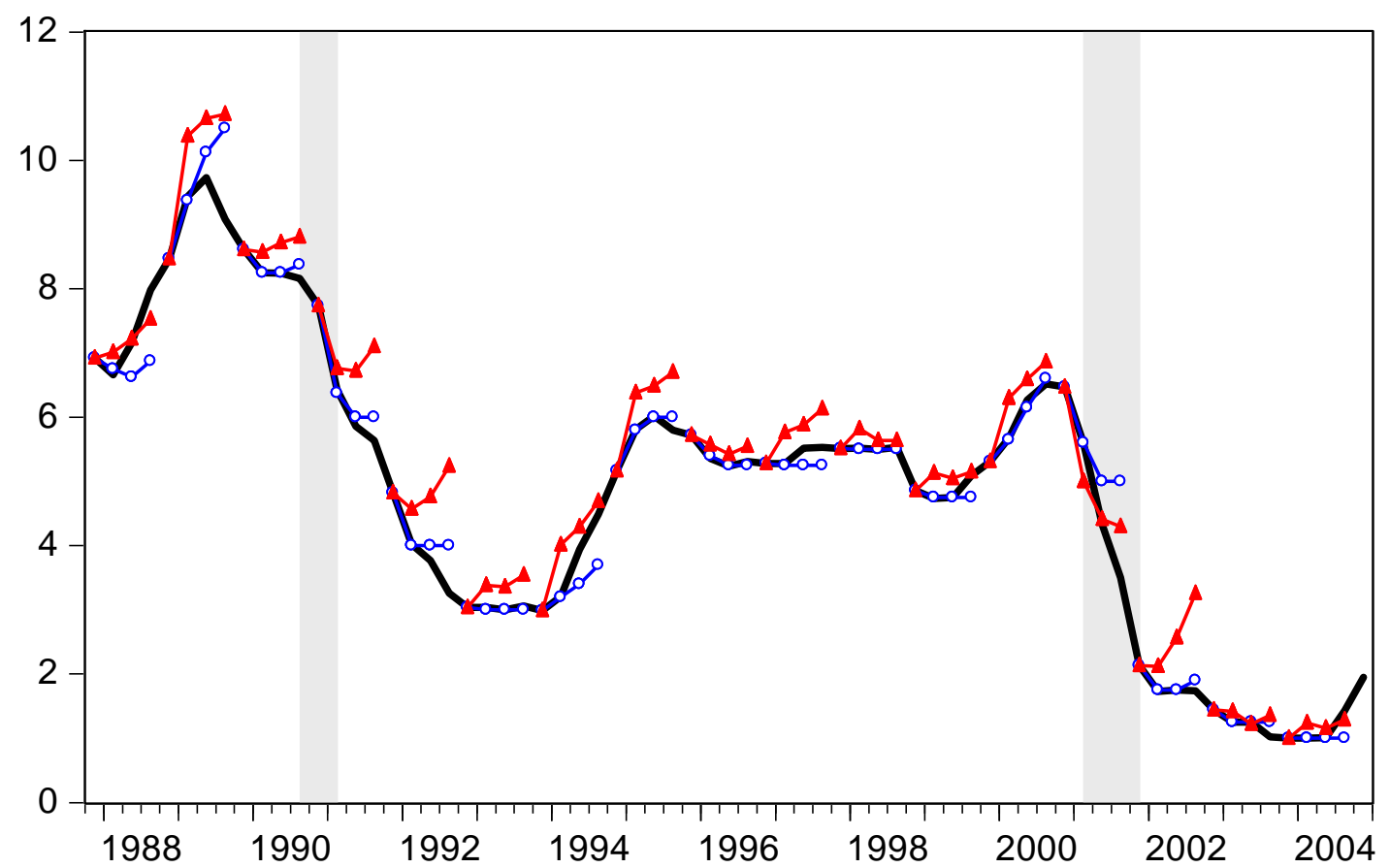

Panel B: Forecasts of the 3-Month TBill Rate from Professional Forecasters and Greenbooks

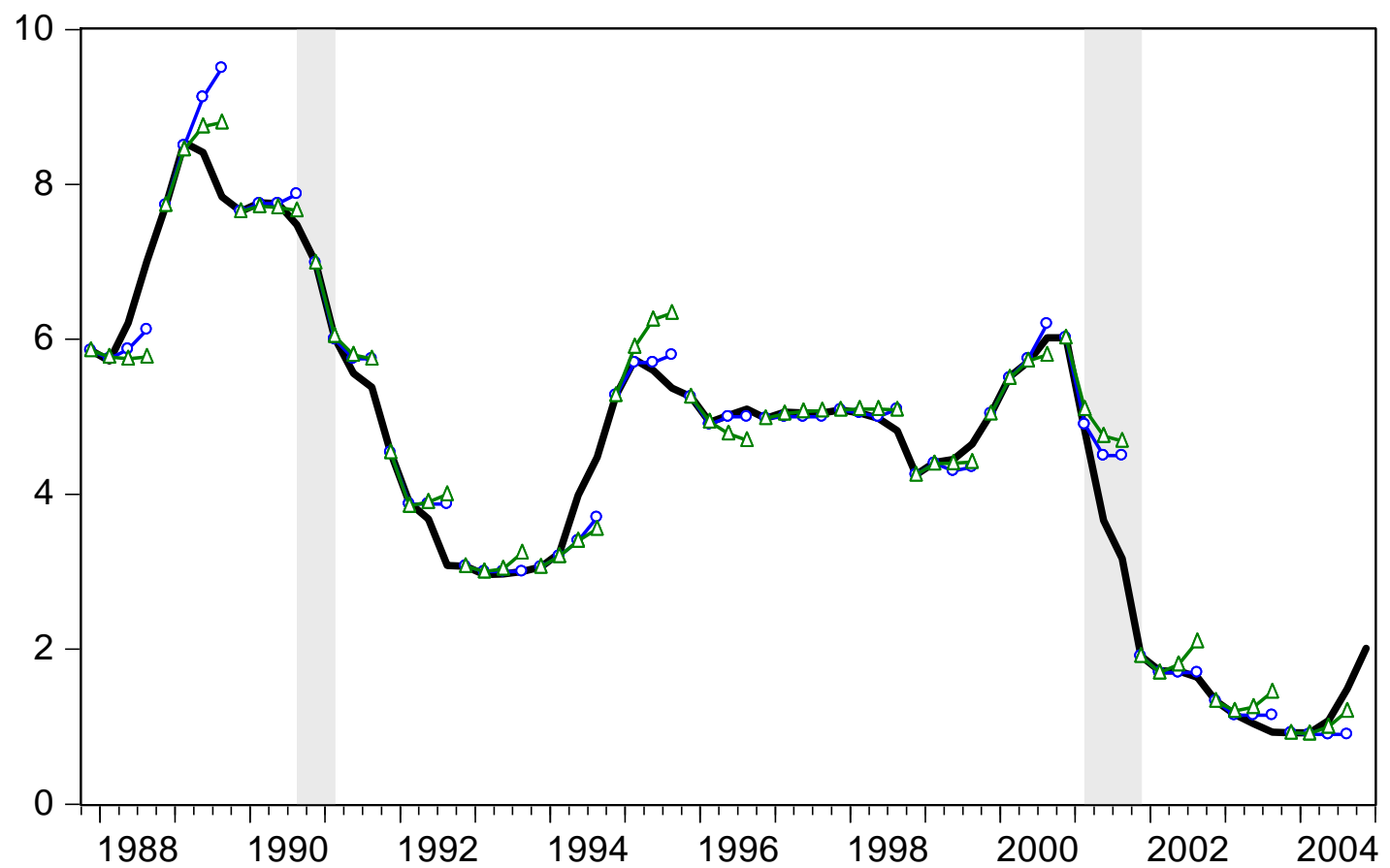

Note: The top figure plots the Federal Funds Rate (black solid line) and the forecasts from the first quarter of each year from financial markets using Eurodollar futures (red lines with triangles) and Greenbooks of the Federal Reserve (blue lines with circles). The bottom figure plots the 3-month TBill rate (solid black line) and the forecasts from the first quarter of each year from the Survey of Professional Forecasters (green lines with triangles) and Greenbooks of the Federal Reserve (blue lines with circles). 
Figure 4: Measures of the Federal Reserve's Target Inflation Rate

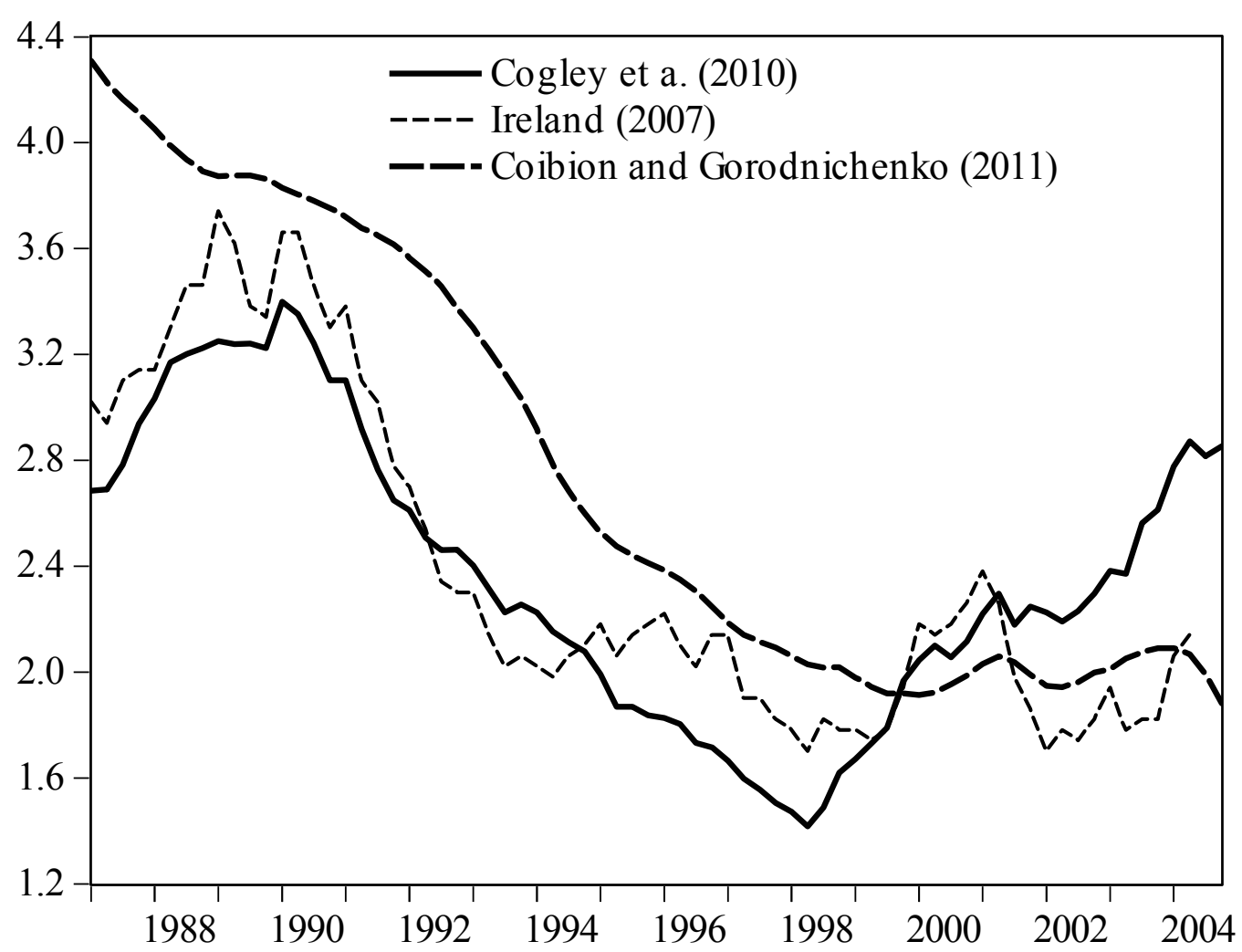

Note: The figure plots the estimates of the annualized inflation target rate of the Federal Reserve from Cogley et al. (2010), Ireland (2007), and Coibion and Gorodnichenko (2011). 
Figure 5: Deviations from the Taylor Rule and Forecast Differentials between Greenbooks and Professional Forecasters

Panel A: Inflation Forecast Differentials

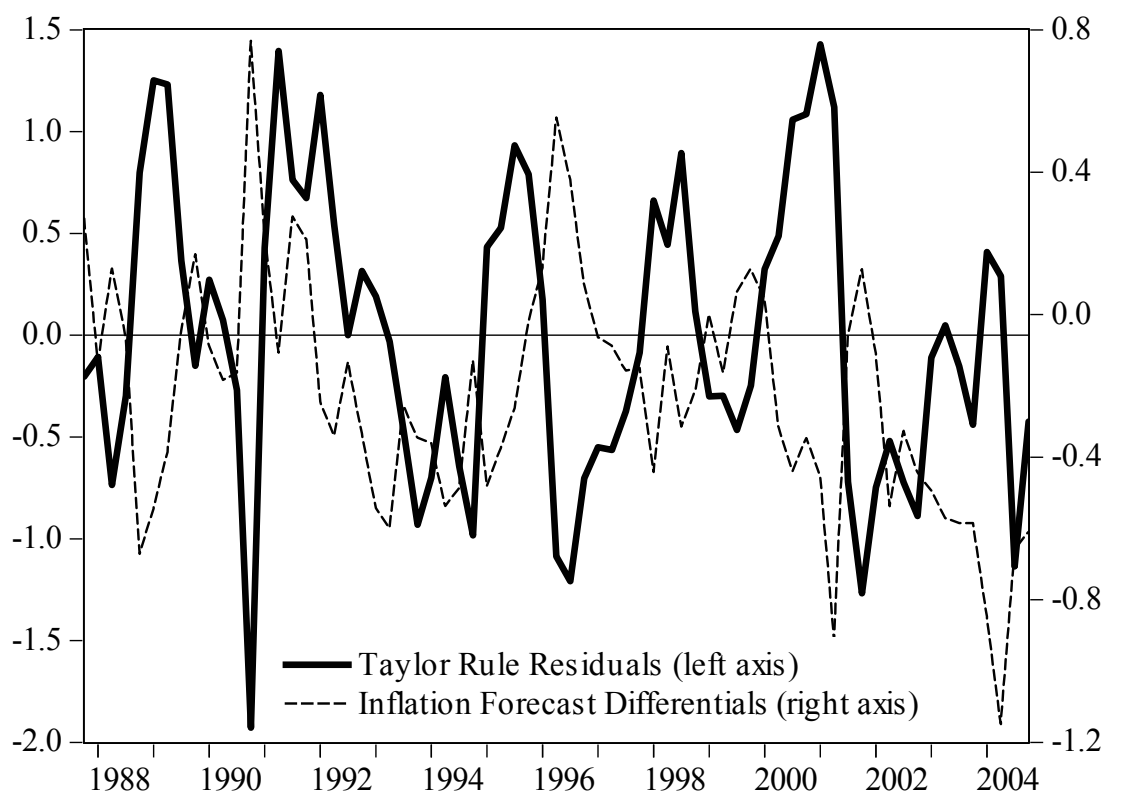

$\underline{\text { Panel B: Output Growth Forecast Differentials }}$

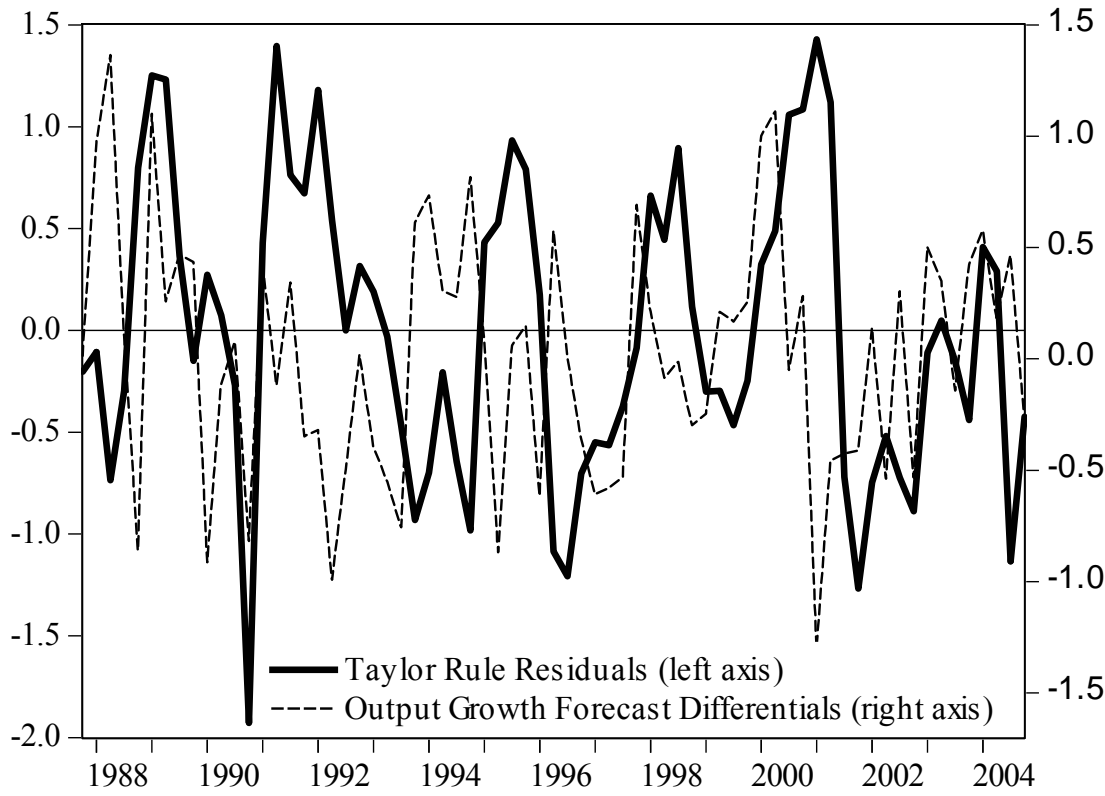

Note: Each figure plots the residuals from the simple Taylor rule in equation (1) in the text, which represent the deviation of actual interest rates from predicted interest rates using only Greenbook forecasts of inflation, output growth, and the output gap. Panel A also includes the difference between the Greenbook forecast of inflation over the next two quarters and the equivalent median forecast from professional forecasts in the SPF. Panel B includes the difference between the Greenbook forecast of output growth in the current quarter and the equivalent median forecast from professional forecasts in the SPF. 
Table 1: Taylor Rule Estimates Nesting Interest Smoothing and Persistent Shocks

\begin{tabular}{cccccc}
\hline \hline & $(1)$ & $(2)$ & $(3)$ & $(4)$ & $(5)$ \\
\hline \hline$\phi_{\pi}: \pi_{t+2, t+1 \mid t}$ & $0.37^{* * *}$ & & $0.48^{* * *}$ & $0.27^{* * *}$ & \\
& $(0.06)$ & & $(0.08)$ & $(0.08)$ & \\
$\phi_{\pi}: \pi_{t+1 \mid t}$ & & $0.25^{* * *}$ & & & \\
& & $(0.05)$ & & & -0.00 \\
$\phi_{\pi}: \pi_{t \mid t}$ & & & & $(0.05)$ \\
& & & & & \\
$\phi_{x}: x_{t \mid t}$ & $0.16^{* * *}$ & $0.13^{* * *}$ & $0.25^{* * *}$ & $0.32^{* * *}$ & $0.25^{* * *}$ \\
& $(0.02)$ & $(0.03)$ & $(0.03)$ & $(0.05)$ & $(0.07)$ \\
$\phi_{g y}: g y_{t \mid t}$ & $0.12^{* * *}$ & $0.14^{* * *}$ & & & $0.07^{* *}$ \\
& $(0.02)$ & $(0.03)$ & & & $(0.03)$ \\
$\phi_{g y}: g y_{t+1 \mid t}$ & & & $0.10^{* * *}$ & & \\
& & & & \\
$\rho_{i}: i_{t-1}$ & $0.81^{* * *}$ & $0.87^{* * *}$ & $0.72^{* * *}$ & $0.65^{* * *}$ & $0.74^{* * *}$ \\
& $(0.03)$ & $(0.04)$ & $(0.03)$ & $(0.07)$ & $(0.09)$ \\
$\rho_{u}: u_{t-1}$ & $0.46^{* * *}$ & $0.44^{* * *}$ & $0.59 * * *$ & $0.85^{* * *}$ & $0.89^{* * *}$ \\
& $(0.11)$ & $(0.12)$ & $(0.09)$ & $(0.08)$ & $(0.06)$ \\
\hline $\mathrm{R}{ }^{2}$ & 0.989 & 0.988 & 0.988 & 0.987 & 0.987 \\
s.e.e. & 0.246 & 0.258 & 0.257 & 0.270 & 0.274 \\
$\mathrm{AIC}$ & 0.120 & 0.213 & 0.206 & 0.292 & 0.330 \\
SIC & 0.314 & 0.407 & 0.401 & 0.454 & 0.524 \\
\hline \hline
\end{tabular}

Notes: The table presents OLS estimates of the Taylor Rule equation (2) in section 2.2 of the text. $\phi_{\pi}$ is the short-run response to inflation expectations, $\phi_{x}$ is the short-run response to the expected output gap, and $\phi_{g y}$ is the short-run response to expected output growth. $\rho_{i}$ is the estimated degree of interest smoothing while $\rho_{u}$ is the persistence of monetary policy shocks. All estimates are done using Greenbook forecasts from 1987Q4 until 2004Q4. ***, and *** denote statistical significance at the $10 \%, 5 \%$ and $1 \%$ levels respectively, using Newey-West HAC standard errors. See section 2.2 for details. 
Table 2: Taylor Rules Nesting Interest Smoothing and Persistent Shocks for Different Time Samples

\begin{tabular}{|c|c|c|c|c|c|c|}
\hline & \multicolumn{3}{|c|}{ Quarterly data } & \multicolumn{3}{|c|}{ Data by FOMC meeting } \\
\hline & $\begin{array}{l}\text { 1987Q4- } \\
\text { 2004Q4 }\end{array}$ & $\begin{array}{c}\text { 1987Q4- } \\
\text { 1999Q4 }\end{array}$ & $\begin{array}{l}\text { 1983Q1- } \\
\text { 2004Q4 }\end{array}$ & $\begin{array}{c}\text { 1987Q4- } \\
\text { 2004Q4 }\end{array}$ & $\begin{array}{c}\text { 1987Q4- } \\
\text { 1999Q4 } \\
\end{array}$ & $\begin{array}{l}\text { 1983Q1- } \\
\text { 2004Q4 }\end{array}$ \\
\hline & (1) & (2) & (3) & (4) & (5) & (6) \\
\hline \multirow[t]{2}{*}{$\phi_{\pi}: \pi_{t+2, t+1 \mid t}$} & $0.37 * * *$ & $0.35 * * *$ & $0.35 * * *$ & $0.26 * * *$ & $0.19 * * *$ & $0.20 * * *$ \\
\hline & $(0.06)$ & $(0.07)$ & $(0.07)$ & $(0.06)$ & $(0.06)$ & $(0.05)$ \\
\hline \multirow{2}{*}{$\phi_{x}: x_{t \mid t}$} & $0.16^{* * *}$ & $0.15^{* * *}$ & $0.08 * * *$ & $0.09 * * *$ & $0.07 * * *$ & $0.05 * * *$ \\
\hline & $(0.02)$ & $(0.03)$ & $(0.02)$ & $(0.02)$ & $(0.02)$ & $(0.01)$ \\
\hline \multirow[t]{2}{*}{$\phi_{g y}: g y_{t \mid t}$} & $0.12 * * *$ & $0.11 * * *$ & $0.20 * * *$ & $0.09 * * *$ & $0.08 * * *$ & $0.12 * * *$ \\
\hline & $(0.02)$ & $(0.03)$ & $(0.02)$ & $(0.01)$ & $(0.02)$ & $(0.02)$ \\
\hline \multirow[t]{2}{*}{$\rho_{i}: i_{t-1}$} & $0.81 * * *$ & $0.80 * * *$ & $0.87 * * *$ & $0.88 * * *$ & $0.90 * * *$ & $0.92 * * *$ \\
\hline & $(0.03)$ & $(0.05)$ & $(0.03)$ & $(0.03)$ & $(0.04)$ & $(0.02)$ \\
\hline \multirow[t]{2}{*}{$\rho_{u}: u_{t-1}$} & $0.46 * * *$ & $0.46^{* * *}$ & 0.19 & 0.07 & 0.02 & $0.18 *$ \\
\hline & $(0.11)$ & $(0.12)$ & $(0.12)$ & $(0.08)$ & $(0.10)$ & $(0.09)$ \\
\hline$\overline{\mathrm{R}^{2}}$ & 0.989 & 0.981 & 0.981 & 0.992 & 0.986 & 0.989 \\
\hline s.e.e. & 0.246 & 0.260 & 0.359 & 0.210 & 0.218 & 0.266 \\
\hline AIC & 0.120 & 0.256 & 0.856 & -0.241 & -0.148 & 0.220 \\
\hline SIC & 0.314 & 0.488 & 1.029 & -0.114 & 0.010 & 0.331 \\
\hline
\end{tabular}

Notes: The table presents OLS estimates of the Taylor Rule equation (2) in section 2.2 of the text. $\phi_{\pi}$ is the short-run response to inflation expectations, $\phi_{x}$ is the short-run response to the expected output gap, and $\phi_{g y}$ is the short-run response to expected output growth. $\rho_{i}$ is the estimated degree of interest smoothing while $\rho_{u}$ is the persistence of monetary policy shocks. $* * *$, and $* * *$ denote statistical significance at the $10 \%, 5 \%$ and $1 \%$ levels respectively, using Newey-West HAC standard errors. See section 2.2 for details. 
Table 3: Information Criteria Selection of Interest Rate Smoothing vs Persistent Shocks

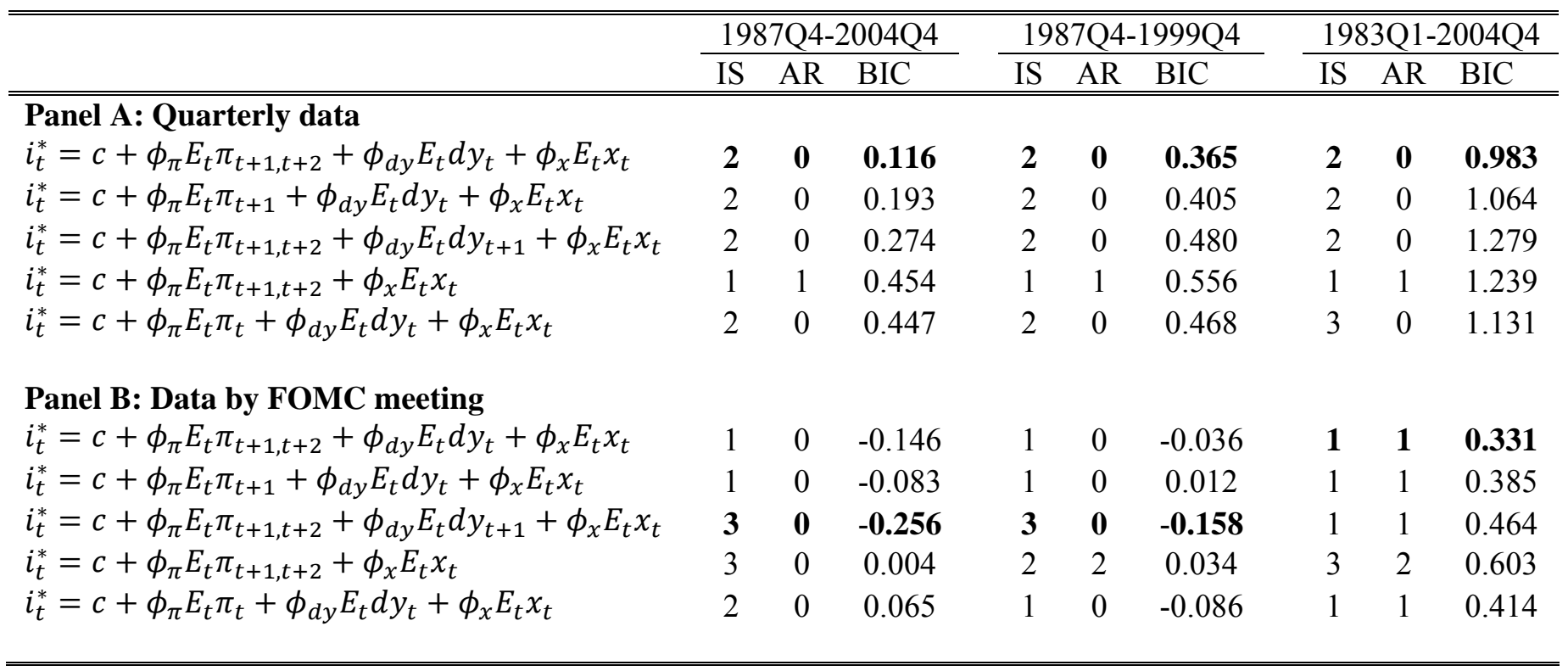

Notes: The table presents the results from specification searches over equation (3) in the text allowing for up to 4 lags of interest smoothing and 4 lags of persistent shocks. For each time period and interest rate rule, we report the preferred specification using the BIC in terms of number of lags for interest smoothing $(I S)$, number of lags for persistent monetary policy shocks $(A R)$ and the BIC statistic associated with the selected specification. Bold values indicate the preferred specification of the Taylor rule according to the BIC criterion for each time sample. See section 3 for details. 
Table 4: Estimates of Taylor Rules with Higher Order Nested Specifications

\begin{tabular}{|c|c|c|c|c|c|}
\hline & $(1)$ & $(2)$ & (3) & (4) & $(5)$ \\
\hline $\bar{\phi}_{\pi}: \pi_{t+2, t+1 \mid t}$ & $\begin{array}{l}0.39 * * * \\
(0.05)\end{array}$ & & $\begin{array}{l}0.50 * * * \\
(0.06)\end{array}$ & $\begin{array}{l}0.46 * * * \\
(0.07)\end{array}$ & \\
\hline$\phi_{\pi}: \pi_{t+1 \mid t}$ & & $\begin{array}{l}0.35^{* * *} \\
(0.05)\end{array}$ & & & \\
\hline$\phi_{\pi}: \pi_{t \mid t}$ & & & & & $\begin{array}{l}0.11 * * \\
(0.05)\end{array}$ \\
\hline$\phi_{x}: x_{t \mid t}$ & $\begin{array}{l}0.11 * * * \\
(0.02)\end{array}$ & $\begin{array}{l}0.11 * * * \\
(0.02)\end{array}$ & $\begin{array}{l}0.18 * * * \\
(0.02)\end{array}$ & $\begin{array}{l}0.16^{* * *} \\
(0.02)\end{array}$ & $\begin{array}{c}0.04 \\
(0.02)\end{array}$ \\
\hline$\phi_{g y}: g y_{t \mid t}$ & $\begin{array}{l}0.13 * * * \\
(0.02)\end{array}$ & $\begin{array}{l}0.13 * * * \\
(0.02)\end{array}$ & & & $\begin{array}{l}0.17 * * * \\
(0.03)\end{array}$ \\
\hline$\phi_{g y}: g y_{t+1 \mid t}$ & & & $\begin{array}{l}0.11 * * * \\
(0.04)\end{array}$ & & \\
\hline$\rho_{i, 1}: i_{t-1}$ & $\begin{array}{l}1.22 * * * \\
(0.08)\end{array}$ & $\begin{array}{l}1.26^{* * *} \\
(0.08)\end{array}$ & $\begin{array}{l}1.21 * * * \\
(0.10)\end{array}$ & $\begin{array}{l}1.30 * * * \\
(0.07)\end{array}$ & $\begin{array}{l}1.31 * * * \\
(0.14)\end{array}$ \\
\hline$\rho_{i, 2}: i_{t-2}$ & $\begin{array}{l}-0.40 * * * \\
(0.07)\end{array}$ & $\begin{array}{l}-0.41 * * * \\
(0.07)\end{array}$ & $\begin{array}{l}-0.45^{* * * *} \\
(0.08)\end{array}$ & $\begin{array}{l}-0.55 * * * \\
(0.07)\end{array}$ & $\begin{array}{l}-0.36^{* * *} \\
(0.12)\end{array}$ \\
\hline$\rho_{u, 1}: u_{t-1}$ & $\begin{array}{l}-0.01 \\
(0.14)\end{array}$ & $\begin{array}{l}-0.08 \\
(0.14)\end{array}$ & $\begin{array}{c}0.00 \\
(0.13)\end{array}$ & $\begin{array}{c}0.01 \\
(0.13)\end{array}$ & $\begin{array}{c}0.13 \\
(0.20)\end{array}$ \\
\hline$\rho_{u, 2}: u_{t-2}$ & $\begin{array}{l}-0.30^{* * *} \\
(0.09)\end{array}$ & $\begin{array}{l}-0.36^{* * *} \\
(0.13)\end{array}$ & $\begin{array}{l}-0.19^{*} \\
(0.11)\end{array}$ & $\begin{array}{l}-0.31 * * * \\
(0.09)\end{array}$ & $\begin{array}{c}0.06 \\
(0.11)\end{array}$ \\
\hline $\mathrm{R}^{2}$ & 0.992 & 0.992 & 0.990 & 0.987 & 0.988 \\
\hline s.e.e. & 0.217 & 0.222 & 0.241 & 0.268 & 0.266 \\
\hline SIC & 0.148 & 0.199 & 0.363 & 0.528 & 0.558 \\
\hline AIC & -0.111 & -0.060 & 0.104 & 0.302 & 0.299 \\
\hline
\end{tabular}

Notes: The table presents estimates of equation (3) in the text assuming two lags of the interest rate for the interest smoothing component $\left(\rho_{i, 1}\right.$ and $\left.\rho_{i, 2}\right)$ and an autoregressive process for the error term of order $2\left(\rho_{u, 1}\right.$ and $\left.\rho_{u, 2}\right)$. All estimates are quarterly, done using Greenbook forecasts, and over the period 1987Q4 to 2004Q4. ***, and *** denote statistical significance at the $10 \%, 5 \%$ and $1 \%$ levels respectively, using Newey-West HAC standard errors. See section 3 for details. 
Table 5: Instrumental Variable Estimation of the Taylor Rule

\begin{tabular}{|c|c|c|c|c|}
\hline & \multicolumn{2}{|c|}{ 1987Q4-2004Q4 } & \multicolumn{2}{|c|}{ 1983Q4-2004Q4 } \\
\hline & OLS & IV & OLS & IV \\
\hline & (1) & (2) & (3) & (4) \\
\hline \multirow[t]{2}{*}{$\phi_{\pi}: \pi_{t+2, t+1 \mid t}$} & $0.42 * * *$ & $0.58 * * *$ & $0.34 * * *$ & $0.57 * * *$ \\
\hline & $(0.05)$ & $(0.14)$ & $(0.07)$ & $(0.13)$ \\
\hline \multirow[t]{2}{*}{$\phi_{x}: x_{t \mid t}$} & $0.14 * * *$ & 0.14 & $0.07 * * *$ & $0.08 * *$ \\
\hline & $(0.02)$ & $(0.09)$ & $(0.01)$ & $(0.03)$ \\
\hline \multirow[t]{2}{*}{$\phi_{g y}: g y_{t \mid t}$} & $0.18 * * *$ & $0.28 * * *$ & $0.22 * * *$ & $0.28 * * *$ \\
\hline & $(0.03)$ & $(0.05)$ & $(0.02)$ & $(0.04)$ \\
\hline \multirow[t]{2}{*}{$\rho_{i}: i_{t-1}$} & $0.82 * * *$ & $0.80 * * *$ & $0.88 * * *$ & $0.80 * * *$ \\
\hline & $(0.03)$ & $(0.10)$ & $(0.03)$ & $(0.05)$ \\
\hline $\mathrm{R}^{2}$ & 0.988 & 0.981 & 0.981 & 0.953 \\
\hline s.e.e. & 0.262 & 0.328 & 0.361 & 0.567 \\
\hline AIC & 0.225 & & 0.857 & \\
\hline SIC & 0.387 & & 0.998 & \\
\hline
\end{tabular}

Notes: The table presents OLS and IV estimates of the Taylor rule in equation (3) in the text. In columns (2) and (4), instruments include a constant and two lags of technology shocks from Gali (1999), TFP residuals from Basu, Fernald and Kimball (2004), oil supply shocks from Kilian (2008), news shocks from Beaudry and Portier (2006), and fiscal shocks from Romer and Romer (2010). ***, and *** denote statistical significance at the $10 \%, 5 \%$ and $1 \%$ levels respectively, using Newey-West HAC standard errors. See section 4 for details. 
Table 6: The Predictability of Interest Rate Changes

\begin{tabular}{|c|c|c|c|c|c|c|}
\hline & \multicolumn{3}{|c|}{ 1987Q4-1999Q4 } & \multicolumn{3}{|c|}{ 1987Q4-2004Q4 } \\
\hline & $i_{t+1}-i_{t}$ & $i_{t+2}-i_{t+1}$ & $i_{t+3}-i_{t+2}$ & $i_{t+1}-i_{t}$ & $i_{t+2}-i_{t+1}$ & $i_{t+3}-i_{t+2}$ \\
\hline & $(1)$ & $(2)$ & (3) & (4) & (5) & (6) \\
\hline Euro-dollar forecasts & $0.81 * * *$ & $0.44 * *$ & 0.35 & $0.99 * * *$ & $0.70 * * *$ & 0.47 \\
\hline of FFR & $(0.17)$ & $(0.18)$ & $(0.29)$ & $(0.11)$ & $(0.22)$ & $(0.30)$ \\
\hline$\overline{\mathrm{R}^{2}}$ & 0.563 & 0.110 & 0.032 & 0.676 & 0.203 & 0.050 \\
\hline Greenbook forecasts & $1.21 * * *$ & $0.95 * * *$ & $1.02 * *$ & $1.29 * * *$ & $0.96^{* * *}$ & $1.00 * *$ \\
\hline of FFR & $(0.16)$ & $(0.24)$ & $(0.50)$ & $(0.12)$ & $(0.22)$ & $(0.44)$ \\
\hline $\mathrm{R}^{2}$ & 0.653 & 0.196 & 0.115 & 0.703 & 0.159 & 0.088 \\
\hline SPF forecasts & $1.45^{* * *}$ & 0.65 & 0.30 & $1.69 * * *$ & $0.85^{*}$ & 0.54 \\
\hline of 3mo T-Bills & $(0.36)$ & $(0.64)$ & $(0.53)$ & $(0.29)$ & $(0.46)$ & $(0.36)$ \\
\hline $\mathrm{R}^{2}$ & 0.330 & 0.042 & 0.010 & 0.425 & 0.066 & 0.040 \\
\hline Greenbook forecasts & $1.13 * * *$ & $0.79 * * *$ & $0.97 *$ & $1.15 * * *$ & $0.86^{* * *}$ & $1.00 * *$ \\
\hline of $3 \mathrm{mo}$ T-Bills & $(0.16)$ & $(0.25)$ & $(0.53)$ & $(0.11)$ & $(0.21)$ & $(0.47)$ \\
\hline $\mathrm{R}^{2}$ & 0.527 & 0.145 & 0.121 & 0.562 & 0.135 & 0.095 \\
\hline
\end{tabular}

Notes: The table reports estimates of equation (8) in the text. The reported coefficients are for the slope of expected changes in future interest rates on the ex-post changes in interest rates for forecasting horizons ranging from one quarter to three quarters. $* * *$, and $* * *$ denote statistical significance at the $10 \%, 5 \%$ and $1 \%$ levels respectively, using Newey-West HAC standard errors. See section 5 for details. 
Table 7: Omitted Variables and the Persistence of Interest Rates

\begin{tabular}{|c|c|c|c|c|c|c|c|}
\hline Dependent variable: $r_{t}$ & $(1)$ & $(2)$ & (3) & (4) & (5) & (6) & (7) \\
\hline$\phi_{\pi}: \pi_{t+2, t+1 \mid t}$ & $\begin{array}{l}0.39 * * * \\
(0.05)\end{array}$ & $\begin{array}{l}0.31 * * * \\
(0.07)\end{array}$ & $\begin{array}{l}0.36^{* *} \\
(0.06)\end{array}$ & $\begin{array}{l}0.51 * * * \\
(0.07)\end{array}$ & & & \\
\hline$\phi_{\pi}: \pi_{t+2, t+1 \mid t}-\pi_{t}^{*}$ & & & & & $\begin{array}{l}0.23 * * * \\
(0.06)\end{array}$ & $\begin{array}{l}0.28 * * * \\
(0.10)\end{array}$ & $\begin{array}{l}0.32 * * * \\
(0.07)\end{array}$ \\
\hline$\phi_{g y}: g y_{t \mid t}$ & $\begin{array}{l}0.13^{* * * *} \\
(0.02)\end{array}$ & $\begin{array}{l}0.12 * * * \\
(0.02)\end{array}$ & $\begin{array}{l}0.12 * * * \\
(0.03)\end{array}$ & $\begin{array}{l}0.15 * * * \\
(0.03)\end{array}$ & $\begin{array}{l}0.17 * * * \\
(0.02)\end{array}$ & $\begin{array}{l}0.18 * * * \\
(0.03)\end{array}$ & $\begin{array}{l}0.17 * * * \\
(0.02)\end{array}$ \\
\hline$\phi_{x}: x_{t \mid t}$ & $\begin{array}{l}0.11 * * * \\
(0.02)\end{array}$ & $\begin{array}{l}0.13 * * * \\
(0.03)\end{array}$ & $\begin{array}{l}0.11 * * * \\
(0.02)\end{array}$ & $\begin{array}{l}0.16 * * * \\
(0.03)\end{array}$ & $\begin{array}{c}0.03 \\
(0.02)\end{array}$ & $\begin{array}{l}-0.01 \\
(0.02)\end{array}$ & $\begin{array}{c}0.03 * \\
(0.01)\end{array}$ \\
\hline$\phi_{r 1}: r_{t-1}$ & $\begin{array}{l}1.22 * * * \\
(0.08)\end{array}$ & $\begin{array}{l}1.17 * * * \\
(0.11)\end{array}$ & $\begin{array}{l}1.24 * * * \\
(0.09)\end{array}$ & $\begin{array}{l}0.98 * * * \\
(0.14)\end{array}$ & $\begin{array}{l}1.28 * * * \\
(0.11)\end{array}$ & $\begin{array}{l}1.31 * * * \\
(0.11)\end{array}$ & $\begin{array}{l}1.31 * * * \\
(0.08)\end{array}$ \\
\hline$\phi_{r 2}: r_{t-2}$ & $\begin{array}{l}-0.40^{* * * *} \\
(0.07)\end{array}$ & $\begin{array}{l}-0.35^{* * *} \\
(0.09)\end{array}$ & $\begin{array}{c}-0.40 * * * \\
(0.08)\end{array}$ & $\begin{array}{l}-0.19 \\
(0.13)\end{array}$ & $\begin{array}{l}-0.35^{* * *} \\
(0.10)\end{array}$ & $\begin{array}{l}-0.34 * * * \\
(0.11)\end{array}$ & $\begin{array}{l}-0.36^{* * *} \\
(0.08)\end{array}$ \\
\hline$\rho_{u 1}: u_{t-1}$ & $\begin{array}{l}-0.01 \\
(0.14)\end{array}$ & $\begin{array}{l}-0.01 \\
(0.16)\end{array}$ & $\begin{array}{l}-0.01 \\
(0.14)\end{array}$ & $\begin{array}{c}0.19 \\
(0.14)\end{array}$ & $\begin{array}{c}0.20 \\
(0.15)\end{array}$ & $\begin{array}{c}0.20 \\
(0.15)\end{array}$ & $\begin{array}{c}0.12 \\
(0.16)\end{array}$ \\
\hline$\rho_{u 2}: u_{t-2}$ & $\begin{array}{l}-0.30 * * * \\
(0.09)\end{array}$ & $\begin{array}{l}-0.26 * * * \\
(0.08)\end{array}$ & $\begin{array}{l}-0.29 * * * \\
(0.09)\end{array}$ & $\begin{array}{l}-0.08 \\
(0.08)\end{array}$ & $\begin{array}{l}-0.06 \\
(0.11)\end{array}$ & $\begin{array}{l}-0.02 \\
(0.11)\end{array}$ & $\begin{array}{l}-0.18^{*} \\
(0.11)\end{array}$ \\
\hline BLOOMSHOCKS $_{t-1}$ & & $\begin{array}{c}0.20 \\
(0.57)\end{array}$ & & & & & \\
\hline $\mathrm{SPREAD}_{t-1}$ & & $\begin{array}{l}-0.02 \\
(0.08)\end{array}$ & & & & & \\
\hline $\mathrm{S} \& P 500_{t-1}$ & & $\begin{array}{l}-0.16 \\
(0.12)\end{array}$ & & & & & \\
\hline$\pi_{t+2, t+1 \mid t}-\pi_{t+2, t+1 \mid t-1}$ & & & $\begin{array}{c}0.14 \\
(0.11)\end{array}$ & & & & \\
\hline$g y_{t \mid t}-g y_{t \mid t-1}$ & & & $\begin{array}{l}-0.01 \\
(0.04)\end{array}$ & & & & \\
\hline$x_{t \mid t}-x_{t \mid t-1}$ & & & $\begin{array}{c}0.01 \\
(0.06)\end{array}$ & & & & \\
\hline$\pi_{t+2, t+1 \mid t}-\pi_{t+2, t+1 \mid t}^{S P F}$ & & & & $\begin{array}{l}-0.31^{* *} \\
(0.14)\end{array}$ & & & \\
\hline$g y_{t \mid t}-g y_{t \mid t}^{S P F}$ & & & & $\begin{array}{l}-0.11 * * * \\
(0.04)\end{array}$ & & & \\
\hline $\mathrm{R}^{2}$ & 0.992 & 0.992 & 0.992 & 0.993 & 0.988 & 0.988 & 0.989 \\
\hline s.e.e. & 0.217 & 0.219 & 0.219 & 0.210 & 0.253 & 0.260 & 0.248 \\
\hline AIC & -0.111 & -0.058 & -0.048 & -0.148 & 0.200 & 0.256 & 0.163 \\
\hline $\mathrm{SIC}$ & 0.148 & 0.298 & 0.307 & 0.176 & 0.459 & 0.515 & 0.426 \\
\hline
\end{tabular}

Notes: Target inflation rate $\pi_{t}^{*}$ in columns (5), (6), and (7) are taken from Cogley et al. (2010), Coibion and Gorodnichenko (2011), and Ireland (2007) respectively. $\pi_{t+2, t+1 \mid t}^{S P F}$ and $g y_{t \mid t}^{S P F}$ are mean forecasts of inflation (two quarters ahead) and output growth rate (current quarter) reported in the Survey of Professional Forecasters. BLOOMSHOCKS are Bloom's (2009) measure of financial uncertainty, SPREAD is the difference between Moody's corporate Baa bonds and 10-year Treasury notes, and S\&P500 is the log of the quarterly average of the S\&P 500 index. . ***, and *** denote statistical significance at the $10 \%, 5 \%$ and $1 \%$ levels respectively, using Newey-West HAC standard errors. See section 6 for details. 